\title{
Review Article Killing Me Softly: Connotations to Unfolded Protein
Response and Oxidative Stress in Alzheimer's Disease
}

\author{
Beata Pająk, ${ }^{1,2}$ Elżbieta Kania, ${ }^{1}$ and Arkadiusz Orzechowski ${ }^{1,2}$ \\ ${ }^{1}$ Electron Microscopy Platform, Mossakowski Medical Research Centre, Polish Academy of Sciences, Pawińskiego 5, \\ 02-106 Warsaw, Poland \\ ${ }^{2}$ Department of Physiological Sciences, Faculty of Veterinary Medicine, Warsaw University of Life Sciences (SGGW), \\ Nowoursynowska 159, 02-776 Warsaw, Poland
}

Correspondence should be addressed to Arkadiusz Orzechowski; orzechowski_arkadiusz@wp.pl

Received 16 October 2015; Revised 28 November 2015; Accepted 7 December 2015

Academic Editor: Federica Rizzi

Copyright (C) 2016 Beata Pająk et al. This is an open access article distributed under the Creative Commons Attribution License, which permits unrestricted use, distribution, and reproduction in any medium, provided the original work is properly cited.

This review is focused on the possible causes of mitochondrial dysfunction in $\mathrm{AD}$, underlying molecular mechanisms of this malfunction, possible causes and known consequences of APP, $\mathrm{A} \beta$, and hyperphosphorylated tau presence in mitochondria, and the contribution of altered lipid metabolism (nonsterol isoprenoids) to pathological processes leading to increased formation and accumulation of the aforementioned hallmarks of AD. Abnormal protein folding and unfolded protein response seem to be the outcomes of impaired glycosylation due to metabolic disturbances in geranylgeraniol intermediary metabolism. The origin and consecutive fate of APP, $\mathrm{A} \beta$, and tau are emphasized on intracellular trafficking apparently influenced by inaccurate posttranslational modifications. We hypothesize that incorrect intracellular processing of APP determines protein translocation to mitochondria in AD. Similarly, without obvious reasons, the passage of A $\beta$ and tau to mitochondria is observed. APP targeted to mitochondria blocks the activity of protein translocase complex resulting in poor import of proteins central to oxidative phosphorylation. Besides, APP, A $\beta$, and neurofibrillary tangles of tau directly or indirectly impair mitochondrial biochemistry and bioenergetics, with concomitant generation of oxidative/nitrosative stress. Limited protective mechanisms are inadequate to prevent the free radical-mediated lesions. Finally, neuronal loss is observed in AD-affected brains typically by pathologic apoptosis.

\section{Introduction}

Alzheimer's disease (AD) is known for almost 120 years as a progressive fatal human neurodegenerative disease featured by decline in both memory and cognitive functions [1]. Earlyonset familial AD (FAD) which accounts for less than $5 \%$ of cases is linked to mutations in APP gene on chromosome 21 or genes encoding components of $\gamma$-secretase (presenilin 1 , presenilin 2) resulting in increased $\mathrm{A} \beta_{42 / 40}$ ratio, where $\mathrm{A} \beta_{42}$ is highly fibrillogenic [2-4]. Sporadic, or late-onset, $\mathrm{AD}$ (SAD) which is a major form (over $95 \%$ of cases) has unknown etiology. While one out of nine people aged 65 or older has Alzheimer's, nearly one out of three people aged 85 or older has the disease [5]. The underlying molecular mechanisms that cause the formation of the hallmarks of FAD and SAD, namely, amyloid- $\beta$ - (A $\beta-)$ containing plaques and microtubule-associated protein tau-containing neurofibrillary tangles (NFTs), are not yet fully clarified. The A $\beta$ peptide is a cleavage product of amyloid precursor protein (APP) by sequential action of $\beta$ - and $\gamma$-secretases which release 3943 -amino-acid peptide from the C-terminal (cytoplasmic) end of transmembrane protein [6]. The outcome of the end-stage intracellular lesions in FAD and SAD is loss of neurons (brain atrophy) with most affected regions as frontal cortex, hippocampus, and amygdala [7]. Severe injuries are very selective and restricted to neurons as shown by the morphometric analyses of brain tissue slices obtained at autopsy from cases with diagnosis of $\mathrm{AD}$ faced up with cases with no clinical or pathological history of neurological disease [8]. Bulk of changes is characterized by significant reduction in mitochondria density, accumulation of mtDNA and proteins in cytoplasm and in the vacuoles associated 
with lipofuscin once involved in mitophagy [9]. These observations show increased mitochondrial degradation products either by autophagy or by messed up proteolytic systems. Mitochondrial abnormalities to milder extent were also found in other cell types (endothelium, fibroblasts) obtained from patients with $\mathrm{AD}[10,11]$. We also observed extensive autophagy in cellular model of FAD and SAD [12].

For decades, the hypothesis of AD ("amyloid cascade hypothesis") of extracellular amyloid- $\beta$ plaques and intracellular NFTs accumulations as clues in $\mathrm{AD}$ pathogenesis have been extensively examined with conflicting results. In the last decade, however, a new attractive hypothesis emerged from studies concerning mitochondria as key organelles for maintaining neuron functions and survival. A growing body of evidence supports the idea that dysfunctional mitochondria cause development of synaptic abnormalities, neuronal degeneration, and ultimately cell death as a consequence of unbearable oxidative stress in AD [13-16]. Numerous in vitro and in vivo experiments substantiated the so-called "vicious cycle hypothesis," pointing to the importance of mitochondria in the pathogenesis of AD [17-28]. Due to their limited glycolytic capacity (lack of salvage pathway), neurons are highly dependent on mitochondrial function for energy release and severely affected by the limited oxygen and glucose supply, making them especially susceptible to energy dyshomeostasis [29]. Moreover, mitochondria, which produce almost entire energy in neurons, have recently been found to be targeted by APP and A $\beta[15,17,30-35]$. The presence of APP and $A \beta$ in mitochondria has detrimental consequences as both constituents cause perturbations in cellular energy homeostasis.

\section{Neurons: Cells Extremely Susceptible to Energy Dyshomeostasis}

Excitability is a basic attribute of neurons (as well as other excitable cells), as it encompasses the primary task to receive, analyze, and dispatch electronic signals within the neuronal network or to their cognate effectors. This function is achieved by the generation of electric currents, some of which are of high frequencies. These electric currents are evoked by the ion fluxes $\left(\mathrm{Na}^{+}, \mathrm{K}^{+}, \mathrm{Ca}^{2+}\right.$, and $\left.\mathrm{Cl}^{-}\right)$through channels located in the plasma membrane. Any change in the concentration of $\mathrm{K}^{+}$or $\mathrm{Na}^{+}$at the extra- or intracellular site of plasma membrane, respectively, activates $\mathrm{Na}^{+} / \mathrm{K}^{+}$-ATPase which restores the concentration gradient essential for excitability and also controls the cell volume. The active transport against the concentration gradient is entirely dependent on ATP delivered to $\mathrm{Na}^{+} / \mathrm{K}^{+}$-ATPase and other pumps $\left(\mathrm{Ca}^{2+}\right.$-ATPase, $\mathrm{H}^{+}$-ATPase). ATP is hydrolyzed leading to phosphorylation of the pump at a highly conserved aspartate residue and subsequent release of ADP. Energy generation and energy consumption are tightly coupled to neuronal activity at the cellular level. $\mathrm{Na}^{+} / \mathrm{K}^{+}$-ATPase, a major energy-consuming enzyme, is well expressed in neurons rich in cytochrome $c$ oxidase, an important enzyme of the energy-generating machinery and glutamatergic receptors that are mediators of neuronal activity [36]. $\mathrm{Na}^{+} / \mathrm{K}^{+}$-ATPase enzyme consumes the bulk of energy in the brain [37-39]. Nervous cells are highly enriched in mitochondria, the main energy supplying organelle, which provide ATP once they are sufficiently supplied with oxygen. Mitochondrial ATP is exchanged with cytosolic ADP through inner membrane adenine nucleotide translocase, so the intracellular location of mitochondria is crucial for availability of ATP and accelerated by cytosolic ADP. To meet energy requirements, mitochondria move regularly along the microtubular meshwork to the sites of higher ATP demand (high concentration of ADP), where they undergo the fusion process. Mitochondrial ATP is also indispensable energy donor for dynamins (kinesin, dynein), the proteins responsible for microtubule-associated axonal transport of the secretory vesicles. Obviously, any substantial interruption of the mitochondrial function, distribution, and fusion would affect the ATP delivery with resultant defects in neuronal activity.

\section{APP Processing and $\mathrm{A} \beta$ Formation}

First, widely expressed APP is a transmembrane glycoprotein, synthesized on three different templates (APP695, APP751, and APP770) which resulted from alternative splicing of the transcript [40,41]. Second, after APP is synthesized on polysomes, this protein undergoes $\mathrm{N}$-glycosylation in the ER. Once it is N-glycosylated, the APP is then transported to the Golgi apparatus. Golgi apparatus is a second chief site of APP posttranslational modifications including $\mathrm{O}-$ and Nglycosylations, phosphorylations, and sulphonations [42, 43]. Great deal of mature APP protein is stored in Golgi and trans-Golgi network (TGN), while approximately $10 \%$ of APP is unidirectionally (anterograde) transported by kinesins in TGN vesicles or in elongated tubular structures along microtubules in soma, dendrites, and axons [44, 45]. Third, APP glycoprotein embedded to plasma membrane is preferentially cleaved in the nonamyloidogenic pathway; alternatively it could be internalized via endocytosis [46]. Endosomic APP protein as well as its processed fragments can return to plasma membrane, can be proteolytically degraded in the lysosome, or can be transported from early endosome to TGN. Retention of APP in the endoplasmic reticulum/intermediate compartment (ER/IC) eliminated production of intracellular $\mathrm{A} \beta_{40}$ but did not alter synthesis of fibrillogenic form $\left(\mathrm{A} \beta_{42}\right)$ [47]. Interestingly, the production of intracellular $A \beta$ from wild-type APP695 appears to be a unique characteristic of postmitotic neurons, since intracellular $A \beta$ was not detected in several nonneuronal cell lines [48]. Whether APP retromer (transported from early endosome to TGN) is also cleaved via amyloidogenic pathway is not clear due to conflicting observations $[49,50]$. In neurons, APP695 is the major isoform and could be subject to sequential proteolytic cleavage by $\beta$ - and $\gamma$-secretase to free $\mathrm{A} \beta$. The $\beta$-secretase (BACE1, transmembrane aspartyl protease) initiates endoproteolytic cleavage giving rise to $\mathrm{N}$-terminus of $\mathrm{A} \beta$ ( $\beta$-secretase cleaved APP to $\beta$ CTF as the intermediate) followed by $\gamma$-secretase (membrane-embedded aspartyl protease complex consisting of presenilin, PS), presenilin enhancer-2 (Pen-2), anterior pharynx defective-1 (Aph-1), and nicastrin, which reveals the C-terminus of A $\beta$ [51]. Given that two PS (PS1 and PS2) and Aph-1 (Aph-1A and Aph-1B) variants exist, the processing 


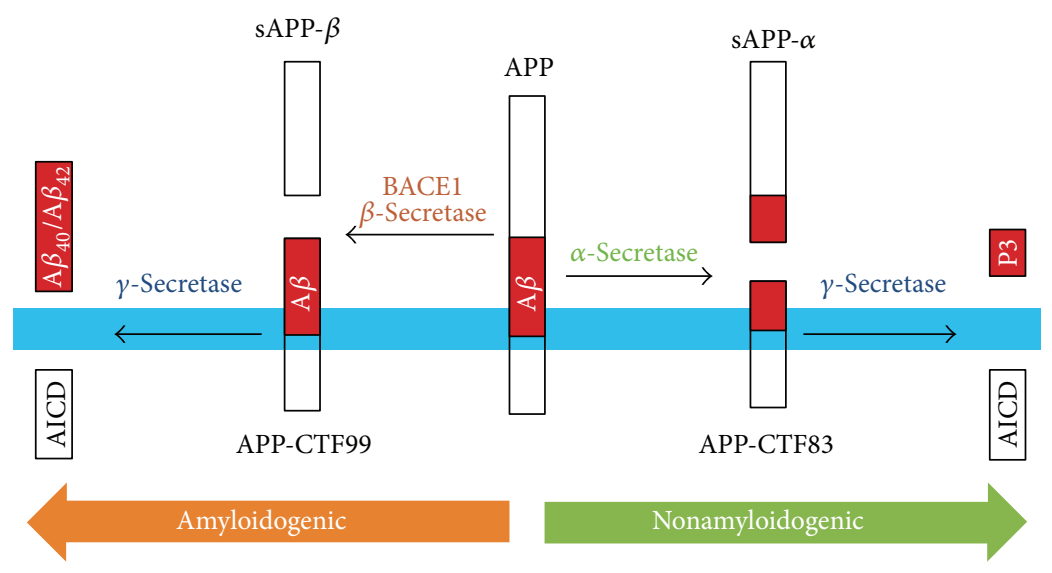

FIGURE 1: A diagram of amyloid precursor protein (APP) processing pathway. The transmembrane protein APP (membrane indicated in blue) can be processed by two pathways: the nonamyloidogenic $\alpha$-secretase pathway and the amyloidogenic $\beta$-secretase pathway. In the nonamyloidogenic pathway, $\alpha$-secretase cleaves in the middle of the $\beta$-amyloid (A $\beta$ ) region (red) to release the soluble APP-fragment sAPP$\alpha$. The APP C-terminal fragment 83 (APP-CTF83, $\alpha \mathrm{CTF}$ ) is then cleaved by $\gamma$-secretase to release the APP intracellular domain (AICD) and P3 fragment. In the amyloidogenic pathway, $\beta$-secretase cleaves APP to produce the soluble fragment sAPP- $\beta$. APP-CTF99 ( $\beta$ CTF) is then cleaved by $\gamma$-secretase to produce $\mathrm{A} \beta_{40}, \mathrm{~A} \beta_{42}$, and AICD. Adopted from [179].

of APP by four different human $\gamma$-secretase complexes each acting at more than one $\beta$ CTF site $\left(\varepsilon^{-}, \zeta\right.$-, and $\left.\gamma^{-}\right)$leads to formation of several $\mathrm{A} \beta\left(\mathrm{A} \beta_{37-43}\right)$, with $\mathrm{A} \beta_{40}$ and $\mathrm{A} \beta_{42}$ being predominant species. Finally, three end products are formed (sAPP- $\beta, \mathrm{A} \beta$, and amyloid precursor protein intracellular domain, AICD). The key neuron $\alpha$-secretase (ADAM10) cleaves APP inside $\mathrm{A} \beta$ polypeptide chain to $\alpha \mathrm{CTF}$ as the intermediate, so after subsequent $\gamma$-secretase action on $\alpha \mathrm{CTF}$, three nonpathogenic fragments are formed (sAPP- $\alpha, \mathrm{P} 3$ fragment, and AICD) (Figure 1).

As aforementioned, FAD is caused by mutations in APP and PSEN genes located on chromosomes 21 and 14, respectively, but the incidence of $\mathrm{AD}$ is also higher in dominantly inherited duplications of the APP locus in elderly individuals with Down's syndrome (trisomy of the 21st chromosome), pointing to important role played by APP and A $\beta$ in AD. Mutations in APP located near the $\beta$-secretase cleavage site increase production of $\mathrm{A} \beta$, whereas those near the $\gamma$-secretase cleavage site result in an increased ratio of $\mathrm{A} \beta_{42}$ to $\mathrm{A} \beta_{40}$ [52]. The $\varepsilon 4$ allele of apolipoprotein $\mathrm{E}$ is the major risk factor for SAD. Thus, this particular APOE gene polymorphism increases disease risk in a dose-dependent manner and lowers the age of onset, as shown by Corder et al. [53]. One copy of APOE4 increases the risk of $\mathrm{AD}$ about fourfold (com-

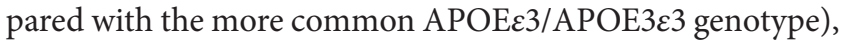
whereas two copies of APOE4 increase the risk of AD about 12 -fold. The mechanism by which the amino acid difference between APOE3 and APOE4 increases the risk of AD remains to be established.

Widespread occurrence of APP and A $\beta$ in nervous system brought about the assumption that both components might play physiological roles. More than few possible concepts have emerged, some validated by experimental data. The APP protein overexpression led to enhanced survival and growth of some cell types $[54,55]$. Furthermore, secreted forms of APP (APPss: sAPP $\alpha$ and sAPP $\beta)$ were antiapoptotic [56] and have a potent neuroprotective action in cultured rat hippocampal and septal neurons and in human cortical neurons [57]. $\mathrm{APP}_{695}^{\mathrm{s}}$ and $\mathrm{APP}^{\mathrm{s}}{ }_{751}$ protected neurons against hypoglycemic damage, and the neuroprotection was abolished by antibodies to a specific region common to both $\mathrm{APP}_{695}^{\mathrm{s}}$ and $\mathrm{APP}^{\mathrm{s}}{ }_{751}$. Thus, $\mathrm{APP}^{\mathrm{s}}$ s may normally play excitoprotective and neuromodulatory roles. Accordingly, APP was shown to stimulate axon branching and the maintenance and formation of synapses, neuronal survival, and neuritic outgrowth [58-60]. APP protein is highly expressed in axons and interacts with extracellular matrix components [61-64]. Similar to APP, A $\beta$ was demonstrated to play a physiological role in synaptic plasticity as minute quantities of the peptide stimulated neurons and enhanced the release of neurotransmitter $[65,66]$. Everything can change when the things go awry.

\section{Perturbations in ER}

In healthy cells including neurons, ER is a fundamental organelle for protein quality control in the secretory pathway, which prevents protein aberrant folding and aggregation [67]. A bulk of evidence shows the importance of ER in APP maturation and processing. With regard to APP intracellular processing, both secretases ( $\alpha$ - and $\beta$-) have been identified in the ER together with $\gamma$-secretase which is present in mitochondria-associated membrane (MAM) subcompartment $[48,68]$. This distinctive intracellular lipidraft-like structure is involved in cholesterol and phospholipid metabolism, $\mathrm{Ca}^{2+}$ metabolism, and mitochondrial dynamics and becomes markedly augmented in AD [69]. MAM is responsible for the communication between the ER and the mitochondria with efficient transfer of $\mathrm{Ca}^{2+}$ from the ER to mitochondria supporting metabolic functions and cell 


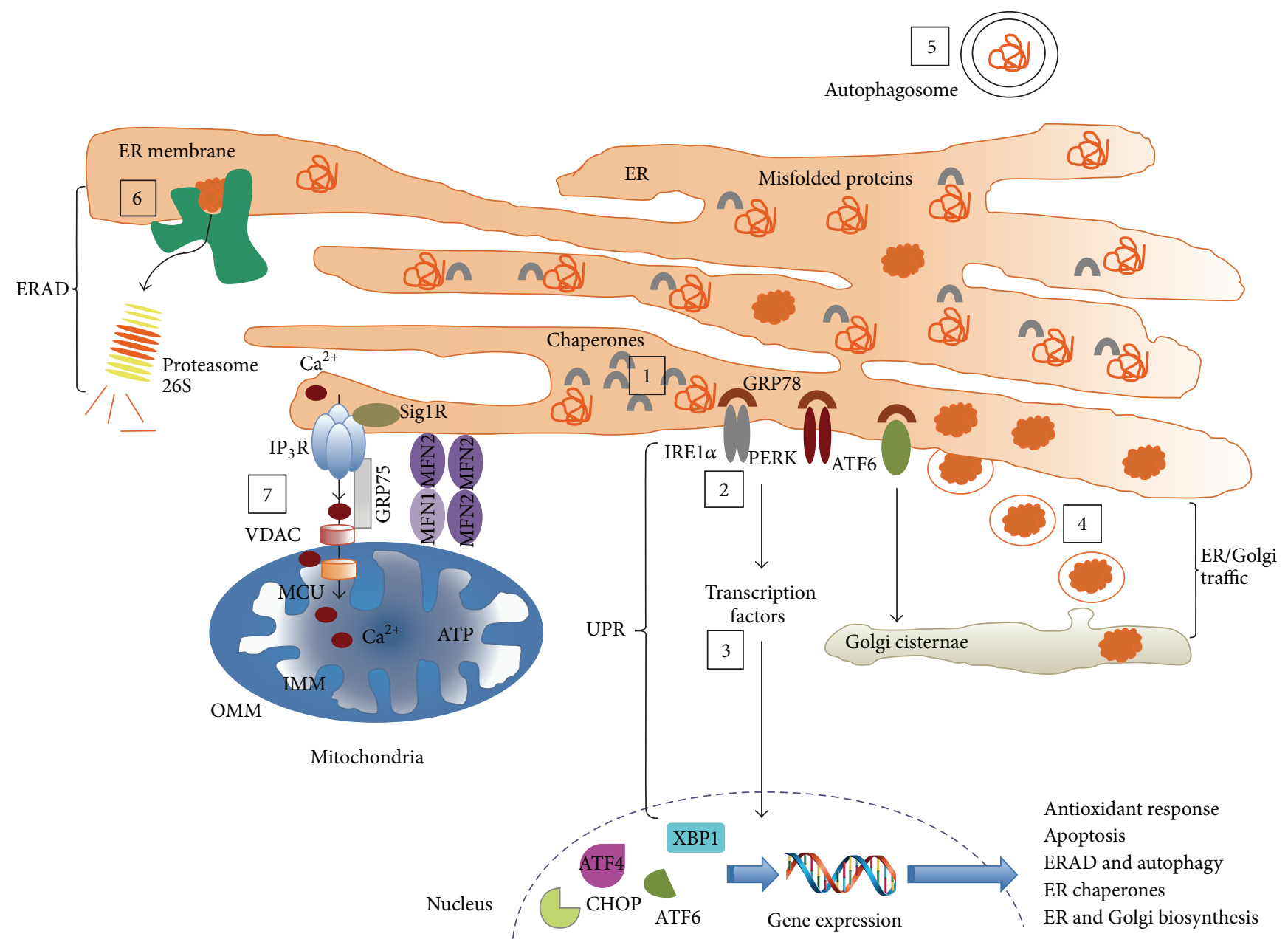

FIGURE 2: ER stress triggered by misfolded proteins in several neurodegenerative diseases. Abnormal conformations of the proteins APP, $\mathrm{A} \beta$, and tau are implicated in the pathogenesis of $\mathrm{AD}$. Alterations in the function of ER chaperones and UPR-related components, ERAD, ER/Golgi trafficking, and ER-to-mitochondria $\mathrm{Ca}^{2+}$ transfer have been suggested as underlying mechanisms of ER stress triggered by these disease-associated proteins. These proteins can accumulate and aggregate at the ER and their stable interaction with ER chaperones such as GRP78/BiP and PDI may trap ER chaperones, altering protein folding with concomitant ER stress. In addition, these proteins can lead to the oxidative modification of the active site of PDIs by nitrosylation leading to their enzymatic inactivation. Furthermore, some of these proteins alter the activity of the UPR stress sensors (IRE1 $\alpha$, PERK, and ATF6) as well as the activity/levels of downstream signaling mediators and transcription factors, including cleaved ATF6, ATF4, and spliced XBP1. As a result, genes implicated in autophagy and ERAD, antioxidant response, ER chaperones, and organelle's biosynthesis are upregulated. Moreover, these proteins block the exit of vesicles from the ER and alter the trafficking between ER and Golgi of properly folded proteins. The cellular responses controlled by UPR transcription factors, including the modulation of autophagy mediated degradation of protein aggregates, become compromised. Disease-related proteins can also interact with ERAD components, precluding the translocation of ERAD substrates from the ER to the cytosol, leading to the accumulation of abnormally folded proteins at the ER. Finally, $\mathrm{Ca}^{2+}$ released from the ER, mainly through the $\mathrm{IP}_{3} \mathrm{R}$, and its transfer to mitochondria can be impaired in the presence of disease-related proteins leading to mitochondrial $\mathrm{Ca}^{2+}$ overload and activation of apoptotic cell death pathways. AD: Alzheimer's disease; ATF6: activating transcription factor 6; ATF4: activating transcription factor 4; ER: endoplasmic reticulum; ERAD: endoplasmicreticulum-associated protein degradation; $\mathrm{IP}_{3} \mathrm{R}$ : inositol triphosphate receptor; IRE1 $\alpha$ : inositol-requiring enzyme 1 alpha; PERK: protein kinase R- (PKR-) like ER kinase; UPR: unfolded protein response; XBP1: Xbox binding protein 1. Adopted from [67].

viability [70]. The molecular bridges between ER inositol 1,4,5-triphosphate receptor $\left(\mathrm{IP}_{3} \mathrm{R}\right)$ and the voltage-dependent anion channels in the outer mitochondrial membrane are brought together through the cytosolic chaperone glucoseregulated protein 75 (GRP75) (Figure 2). Additionally, the dynamin-related GTPase mitofusin 2 (Mfn2) proteins located on the ER intermingle with Mfn1 or Mfn2 on mitochondria to tighten the connection. The distance between ER and mitochondria controlled by the phosphofurin acidic cluster sorting protein 2 (PACS-2) of ER and the dynamin-related GTPase protein 1 (Drpl) is crucial for cell survival, as either too long (lack of $\mathrm{Ca}^{2+}$ flux) or too short distance $\left(\mathrm{Ca}^{2+}\right.$ overload) might lead to apoptosis [71]. Alternatively, impaired mitochondrial bioenergetics with reduced cellular ATP 
levels stimulate autophagy. The molecular mechanism of ERmediated autophagy is accurately regulated by Beclin 1 as well as ER membrane bound protein Bax inhibitor 1 (BI-1). Both proteins are capable of promoting autophagy through $\mathrm{IP}_{3} \mathrm{R}-$ dependent mechanism [72].

\section{APP Processing and ER Stress Response}

The nature of APP processing is determined by the composition of membrane, with cholesterol rich lipid rafts as the site of amyloidogenic cleavage [73]. Consequently, one might expect that fate of APP is at least partly established by the representation of lipid rafts and possible access to $\beta$ versus $\alpha$-secretase. Irrespective of the type of cleavage, there is one underestimated biochemical step in ER that might bring about damaging upshot. It is apparently the effectiveness of ER situated N-glycosylation which makes the APP molecule suitably folded. If misfolded/malfolded protein(s) accumulate in the ER, complex cascade of reactions known as the unfolded protein response (UPR) is triggered with the socalled endoplasmic reticulum stress response (ERS). Today, it is widely accepted that, during UPR, the ER sensors, protein kinase R- (PKR-) like ER kinase (PERK), activating protein kinase 6 (ATF6), and inositol-requiring enzyme 1 alpha (IRE1 $\alpha$ ), are freed from GRP78/BiP protein repression, which hereafter become activated. Without going into details of individual sensor action, a number of reactions occur at both the genomic and cytoplasmic level with selective degradation of mRNAs encoding protein(s) with abnormal folding and inhibition of protein translation, except for genes important for UPR, redox homeostasis, energy metabolism, and protein folding [67]. On the one hand, PERK phosphorylates eukaryotic initiation factor 2 alpha (eIF2 $\alpha$ ) to stop entrance of methionyl-tRNA to the ribosome; on the other hand, it allows translation of activating transcription factor 4 (ATF4) gene. IRE1 $\alpha$ sets off alternative splicing of Xbox binding protein 1 (XBP1) transcript leading to activation of the transcription factor liable to stimulate ER/Golgi biogenesis and formation of proteins involved in endoplasmic-reticulum-associated protein degradation known as ERAD (Erdj4, p58 $8^{\mathrm{IPK}}$, EDEM, RAMP-4, PDI-P5, and HEDJ; for details, see [67]). Finally, ATF6 is activated in the Golgi complex through proteolytic cleavage and translocates to nucleus where it cooperates with $\mathrm{XBP} 1$ in upregulation of chaperones and ERAD-related genes [43]. In principle, UPR is activated to restore ER homeostasis and stop the accumulation of aberrantly formed protein(s) but if the strength of ER stress is unbearable (meaning that it cannot be compensated by UPR) there is a path to activate apoptosis. Among other routes the most central role is played by the major proapoptotic transcription factor C/EBP homologous protein $\mathrm{CHOP} /$ growth arrest and DNA damage induced gene 153 GADD153. It downregulates the antiapoptotic protein $\mathrm{Bcl}-2$ and upregulates proapoptotic $\mathrm{Bax}$ and $\mathrm{Bak}$ [74]. CHOP/GADD153 leads to excessive production of reactive oxygen species (ROS) within ER, subsequent depletion of reduced glutathione (GSH) and $\mathrm{Ca}^{2+}$ flux from the ER to cytoplasm through the $\mathrm{IP}_{3} \mathrm{R}$ [75]. One hitherto unresolved issue is the physiologic importance of APP and GRP78/BiP interaction disclosed in coprecipitation study carried out by
Yamamoto et al. [76]. Bulk of APP associated with GRP78/BiP was immature protein. Given that GRP78/BiP expression levels declined in samples of brain tissue obtained from FAD patients as demonstrated by Katayama et al. [77], few distinct scenarios are possible. First, binding to GRP78/BiP suggests ER accumulation of immature APP. Second, APP interaction with GRP78/BiP is a noticeable sign of UPR which is further validated by downregulation of GRP78/BiP in FAD patients. Finally, retention of APP in ER is most likely a result of amyloidogenic APP processing and as such it probably occurs in MAM, the cholesterol enriched domains. ER-mitochondria crossing point is therefore of particular interest in deciphering the links between the ER placed APP processing, UPR, and resulting cellular responses such as autophagy, apoptosis, and inflammatory reaction observed in $\mathrm{AD}$ (Figure 2).

\section{Pathology of Tau Protein}

Microtubule-associated protein tau controls assembly and prevents microtubules from severing. Microtubular network is fundamental component of cytoskeleton essential for intracellular transport of secretory vesicles and organelles (i.e., mitochondria). Glycogen synthase kinase 3 beta- (GSK$3 \beta$-) targeted hyperphosphorylation of tau causes this protein to dissociate from microtubules. Consequently, microtubules become fragmented and microtubule-dependent transport system fails. Furthermore, hyperphosphorylated tau (P-tau) is prone to form oligomers and toxic filaments, known as NFTs or tauopathy [78]. A variety of tau conformers were reported to exist, pointing to different tauopathies capable of self-propagation $[79,80]$. Interestingly, intracellular tau inclusions define $\mathrm{AD}$ as clinical symptoms of disease observed when tauopathy is abundant together with intracellular $\mathrm{A} \beta$ deposits in neocortex $[51,81,82]$. People with abundant $A \beta$ plaques, but no or only a few neurofibrillary lesions, do not have AD. Clinicopathological correlation studies have been crucial to generate hypotheses about the pathophysiology of the disease, by establishing the fact that there is a continuum between "normal" aging and $\mathrm{AD}$ dementia and that the amyloid plaque buildup occurs primarily before the onset of cognitive deficits, while neurofibrillary tangles, neuron loss, and particularly synaptic loss parallel the progression of cognitive decline [83]. Thus, misfolded proteins and descendant toxic filaments with a number of intermediates are critical for manifestation of $\mathrm{AD}$, as fibrillogenic APP processing is not enough for onset of disease. Although the molecular mechanism of tauopathy is not deciphered in full, recent reports suggest ER stress as the starting point $[84,85]$. This idea is substantiated by the elevated levels of ERS and UPR markers together with P-tau and GSK- $3 \beta$ in brains affected by $\mathrm{AD}$ [86]. Therefore, on the one hand, the incidence of UPR is strongly correlated with the presence of NFTs; on the other hand, aggregation of P-tau induces ERS with resultant UPR. Some lines of evidence confirmed UPR activation near the beginning of NFTs formation and point to the functional link between malformed tau protein and UPR. The in vitro experiments with phosphatase $2 \mathrm{~A}$ inhibitor or phosphorylation activator demonstrated enhanced P-tau 
formation in neurons in concert with the increased levels of PERK, eIF $2 \alpha$, and XBP1 transcript, apparent markers of UPR [87]. Furthermore, GRP78/BiP was found to encourage tau phosphorylation through facilitated substrate capture by GSK-3 $\beta$ [88]. GSK- $3 \beta$ seems to play dual role; first this kinase protects neurons from apoptosis as P-tau accumulation is strong molecular signal to trigger UPR with subsequent autophagy. Second, UPR raises GSK-3 $\beta$ activity through lysosomal degradation of inactive GSK-3 $\beta$ (P-Ser9-GSK-3 $\beta$ ). To sum up, ERS and UPR are important molecular machines used to prevent cell viability turned on by tauopathy.

\section{Oxidative Stress in ER}

Sacs and tubes of ER delineate the compartment where the newly synthesized proteins undergo maturation to native state. Native state indicates properly folded, fully functional protein. Important reactions essential for protein folding of unbranched polypeptide chains include amino acids oxidation and glycosylation. As a result, redox homeostasis in ER is shifted to oxidative state so as to promote disulfide bond formation between adjacent cysteines. Oxidation of sulfhydryl groups required to make disulfide bonds is controlled by ER oxidase $1 \alpha$ (ERO1 $\alpha)$. Next, disulfide bonds could be subject to posttranslational modification, disulfide exchange by protein disulfide isomerase (PDI). PDI is able to correct mispaired thiol residues by catalyzing the breakage and formation of correct disulfide bonds. These enzymes are fundamental for protein folding. Oxidation allows twisting of proteins, which is followed by N-glycosylation and/or Cand O-mannosylation. Protein N-glycosylation in eukaryotes is a complex process divided into several steps. First, there is a "call for" carrier lipids (polyisoprenyl phosphates such as dolichyl phosphates), the membrane lipids known to function as glycosyl transporters. In mammalian cells, the limiting substrate for dolichol biosynthesis is geranylgeraniol (GGOH) of mevalonate pathway. Dolichols, the longest aliphatic molecules synthesized in animal cells, have 18-21 $\alpha$-isoprene saturated units (C90-105), critical for their recognition by the enzymes (glycosyltransferases) that glucosylate dolichyl phosphates [89]. Once dolichyl monophosphates (Dol-P) are formed in the ER membrane, the precursor oligosaccharide donor $\left(\mathrm{GLc}_{3} \mathrm{Man}_{9} \mathrm{GLCNAc}_{2}-\right.$ P-P-dolichol) for protein N-glycosylation can be synthesized on the lumenal leaflet of ER. First, three sugar intermediates are produced (Man-P-Dol, Glc-P-Dol, GlcNAc-P-P-Dol, and $\mathrm{Man}_{5}$ GlcNAc-P-P-Dol) on the cytoplasmic leaflet of the ER. Next, enzyme flippases mediate transbilayer movement of the aforementioned intermediates to lumenal side of ER where conversion to $\mathrm{Glc}_{3} \mathrm{Man}_{9} \mathrm{GlcNAc}_{2}$-P-P-Dol could be completed. $\mathrm{Glc}_{3} \mathrm{Man}_{9} \mathrm{GlcNAc}_{2}$-P-P-Dol is also used for biosynthesis of glycosylphosphatidylinositol (GPI) anchors.

Taken together, lipid-mediated glycosylation plays a vital role in the appropriate protein folding and intracellular translocation of N-linked glycoproteins [90]. Likewise, it is important for protein O- and C-mannosylation, and GPI anchorage. Moreover, Dol-P availability in the ER is the ratelimiting factor in the production of glycolipid intermediates and N-glycosylation.

\section{ER Stress and Apoptosis}

It was shown that during ERS the ER resident proapoptotic cysteine protease known as caspase (caspase-12 in rat, caspase- 4 in humans) is activated through cleavage. As a result caspase cascade is started via caspase- 9 that in turn stimulates effector caspase-3 [91, 92]. The central role played by ER in programmed cell death is achieved by PERK branch where ATF4 induces the expression of CHOP/GADD153, which represses antiapoptotic Bcl-2 family proteins and simultaneously shuffles ER membrane Bax and Bak proteins into outer mitochondrial membrane. Consequently, pores are formed to leak the components of apoptosome from mitochondrial intermembrane space [93]. Another important mechanism of ERS-induced apoptosis is led by $\mathrm{Ca}^{2+}$ dependent ERO1 $\alpha$-IP ${ }_{3} \mathrm{R}$ pathway where ERO1 $\alpha$ collaborates with $\mathrm{IP}_{3} \mathrm{R}$ in $\mathrm{Ca}^{2+}$ efflux from ER to mitochondria via MAM $[75,94]$. Accordingly, $\mathrm{Ca}^{2+}$ influx facilitates cytochrome $c$ release from mitochondria; besides, cytochrome $c$ can bind to ER $\mathrm{IP}_{3} \mathrm{R}$ and the complex amplifies the apoptotic signal in a feedforward manner [95]. Last but not least, ERS-associated apoptotic programme is set off by c-Jun N-terminal kinase (JNK) as the effect of IRE1 $\alpha$ complexed with TNF-receptorassociated factor 2 (TRAF2) activation of apoptosis-signalregulating kinase 1 (ASK1) $[96,97]$.

What does ERS drive to induce apoptotic death in neurons? Actually, many reports indicate that APP and A $\beta$ as well as hyperphosphorylated tau have been shown to block mitochondrial transport, which results in impaired energy storage and oxidative stress [98-101]. Indeed, accumulation of APP, $\mathrm{A} \beta$, and NFTs in mitochondria led to reduced activity of some enzymes involved in substrate oxidation (tricarboxylic acid cycle), electron transport chain (ETC), and ATP synthase, as well as severely diminishing import of nuclear-encoded proteins [26, 27, 102-104]. One may ask if there is any additional link between ER and mitochondria other than MAM which could account for apoptotic signal. Though not directly, ER significantly contributes to oxidative stress in mitochondria of $\mathrm{AD}$-affected subjects.

\section{Abnormal APP Processing and Trafficking Culminate in ER Pathology of AD}

From the morphological point of view, as neurons are highly specialized cells, soma, dendrites, and neurites are considerably distinct structures. Proteins needed by these compartments are delivered via microtubules once proteins have suitable sorting signals (i.e., APP trafficking from ER to plasma membrane is associated with several posttranslational modifications with oxidation and N-glycosylation). Additionally, the Golgi apparatus follows ER in subsequent APP adjustment (O- and N-glycosylation, phosphorylation, and sulphonation) [42]. Any inaccurate alteration of the APP molecule is potentially hazardous, as protein final destiny is missed causing its retention in ER or trans-Golgi network (TGN). In addition, other unusual settings for APP are possible as this large protein has few signal sequences hidden when APP is correctly folded. In the cells transfected with APP, this protein enters coat protein complex I (COPI) 
vesicles and undergoes retrograde transport from cis end of the Golgi complex back to the ER [76]. Such response causes accumulation of APP in the tubulocisternal ER system together with aberrant intracellular translocation of the protein. Interestingly, the issue whether APP is subject to retrograde transport with successive fibrillogenic processing because of UPR and its interaction with GRP78/BiP is not clear, as the observations are inconsistent [77]. Nonetheless, accumulation of misfolded/malfolded proteins in the ER suggests disorganized process of posttranslational change. As anticipated, the accretion of proteins of anomalous pattern signals ERS and UPR followed by increased vulnerability to apoptotic cell death. Prior to decay, however, APP protein levels in the ER lessen by dint of cleavage with $\beta$ - and $\gamma$-secretase $[105,106]$. Products of this cleavage $(\operatorname{sAPP} \beta$, $\mathrm{A} \beta$, and AICD fragment) all appreciably influence neuronal survival most likely through nonnative form of the APP substrate.

\section{APP, $A \beta$, and NFTs Mark Mitochondria as Targeted in AD}

Mitochondrial import of $A \beta_{40}$ and $A \beta_{42}$ peptides through the translocase TOM complex was blocked by preincubation of isolated mitochondria with antibodies raised against TOM proteins (TOM20, TOM40, and TOM70) [107]. Neither VDAC inhibition with antagonist antibodies nor inhibition of mitochondrial permeability transition pores (MPTP) or fall of mitochondrial membrane potential (MMP) affected uptake of $\mathrm{A} \beta$ [17]. With regard to APP, elegant study performed by Anandatheerthavarada and his colleagues [30] revealed that C-terminal truncated APP (lacking $\mathrm{A} \beta$ ) targets mitochondria in cholinergic, GABAergic, dopaminergic, and glutamatergic neurons of $\mathrm{AD}$ brain by clogging up mitochondrial protein translocase complex TOM40/TIM22. Authors propose that occlusion of translocase is followed by blunted import of nuclearencoded proteins vitally important for energy homeostasis. Mitochondrial APP protein transmembrane orientation indicates $\mathrm{NH}_{2}$-terminal inside in contact with translocase, whereas $\mathrm{COOH}$-terminal is facing cytoplasmic side. $\mathrm{NH}_{2}$ terminus has mitochondrial signal sequence. Astonishingly, mitochondrial APP molecules were nonglycosylated giving rise to speculation that protein molecules that arrived at mitochondria have not achieved molecular maturity [31]. The accumulation of nonglycosylated APP species in mitochondrial import channels of $\mathrm{AD}$ brain was directly related to decreased mitochondrial functions as validated by the decline in cytochrome $c$ oxidase activity (complex IV) and elevated levels of $\mathrm{H}_{2} \mathrm{O}_{2}$. Furthermore, in $\mathrm{AD}$ brain, the mitochondrial accumulation of nonglycosylated APP went along with a corresponding reduction in plasma membrane-associated APP. It suggests that AD brain has APP processing and trafficking severely affected by incomplete $\mathrm{N}$-glycosylation, ensuing ER protein accumulation and exposure of the cryptic mitochondrial targeting signal for assisting chaperone proteins. Several lines of evidence indicate that not fully formed proteins are phosphorylated and bind to the cytosolic proteins required for movement from ER to mitochondria [108-110]. Moreover, ERS and UPR in $A D$ seem to be incompetent and inefficient in elimination of malfolded proteins. In addition to APP also $\mathrm{A} \beta$ was frequently reported to occupy mitochondria although its origin and mechanism of mitochondria targeting mostly remain unexplored (except for involvement of protein translocase TOM complex). The possibility of mitochondrial $\mathrm{A} \beta$ generation has to be ruled out, as membrane orientation of arrested APP does not allow access to $\gamma$-secretase $(\gamma$-secretase activity in mitochondria was detected by independent study) [111]. Probably, A $\beta$ species is derived from APP prior to its translocation (ER?), so $\mathrm{A} \beta$ may be transported to mitochondria independently of APP. Collectively, observations showing mitochondrial presence of $\mathrm{APP}, \mathrm{A} \beta$, and tau in aberrant configuration point toward the anomaly of protein folding at the level of ER and Golgi apparatus. Nonglycosylated molecule of APP suggests defective transfer of sugar core from dolichyl phosphate(s) and further modifications such as $\mathrm{O}$ - and $\mathrm{N}$-glycosylations. One may admit that the lack of glycosyl residue brings about pathologic processing and trafficking of APP and its fragments. In point of fact, dolichol derivatives, mixture of polyprenols (acyclic isoprenoid alcohols) known as Ropren (Solagran Limited, Melbourne, Australia) commercially used to treat liver diseases, were tested in the treatment of AD in two separate trials conducted in 2005 and 2006 with promising results [http://www.asx.com.au/asxpdf/20071119/ pdf/315x5nh4hm8wv7.pdf, http://www.asx.com.au/asxpdf/ 20070221/pdf/3111ztwcbqzkk9.pdf]. Further studies are urgently needed to test how important the glycosylation process is in the pathogenesis of $\mathrm{AD}$. Dolichols are obtained from geranylgeraniol (GGOH) and the latter is an intermediate of mevalonate pathway. GGOH is a common substrate for dolichol and ubiquinone synthesis, but it is also necessary for protein prenylation. As both GGOH and farnesol $(\mathrm{FOH})$ are engaged in protein prenylation more concern should be laid on the importance of these compounds in $\mathrm{AD}$ pathogenesis. Observations demonstrating mitochondrial relocalization of other proteins without posttranslational modification seemingly point to increased mitochondrial targeting of immature molecules resulting in mitochondrial dysfunction and acceleration of disease progression [34, 112-114].

\section{Oxidative Stress in Mitochondria of AD Brains}

Normal physiological functions of APP are thought to be involved in the stabilizing contact points between synapses and maintaining mitochondrial functions $[60,115]$. Mitochondrial dysfunction was often observed regardless of the experimental model used to study $\mathrm{AD}[8,29,116-119]$. It includes defects in oxidative phosphorylation, decreased ATP, decreased membrane potential, increased production of ROS/RNS, and perturbation in mitochondrial fusion and fission [15, 30, 31, 115, 120-122]. Hyperphosphorylated tau was also reported to impair mitochondrial functions [123]. Using proteomic approach, the strongest defects of the respiratory capacity were observed mainly at complexes I, IV, and ATP 
synthase (complex V) at both protein and activity level [124]. While APP, A $\beta$, and hyperphosphorylated tau are potent inhibitors of mitochondrial import of nuclear-encoded proteins, apparently the pathology of each leads to metabolic harm in different way. In freshly isolated mitochondria from $\mathrm{AD}$ brains, the APP inhibited mitochondrial import of cytochrome $c$ oxidase (COX) subunits IV and $\mathrm{Vb}$ [31]. Dysfunction of COX increases ROS production (incomplete reduction of oxygen molecules), reduces energy stores, and disturbs energy metabolism. Accordingly, in AD patients, deficiency of COX was found in brains and platelets [119, $125,126]$. Similar to APP, A $\beta$ was found in mitochondria of transgenic mice and cellular and human AD models [17, $19,33,103,127-130]$. At present it is not clear whether the observed mitochondrial toxicity is due to APP or $\mathrm{A} \beta$, or NFTs accumulation. Anyway, some regularity is observed with respect to most affected components of respiratory chain. $\mathrm{NADH}$-ubiquinone oxidoreductase (complex I) activity is reduced to the utmost by hyperphosphorylated tau, whereas decreased activity of cytochrome $c$ oxidase (complex IV) that resulted in mitochondrial dysfunction was observed during $\mathrm{A} \beta$ and APP accumulation [14, 15, 31, 32, 34]. Concomitantly, rise in the activity of antioxidant enzymes manganese superoxide dismutase (Mn-SOD) and catalase (CAT) was demonstrated in response to elevated levels of free radicals including superoxide anion radical $\left(\mathrm{O}_{2}{ }^{--}\right)$, hydroperoxyl radical $\left(\mathrm{HO}_{2}{ }^{\circ}\right)$, hydroxyl radical $\left(\mathrm{OH}^{\circ}\right)$, and nitric oxide radical $\left(\mathrm{NO}^{\circ}\right)$ [15]. Consistent with observations of chronic respiratory chain dysfunction and mitochondrial oxidative stress, there are reports showing their contribution to tau pathology in $\mathrm{AD}$ [131]. In any case, free radicals that override antioxidant defense react with a wide variety of organic components causing lipid peroxidation to advanced lipid oxidation end products (ALE), cross-linking of proteins, nitrosylation of proteins, and mutations in DNA. Mitochondrial circular DNA (mtDNA) of $~ 16 \mathrm{kbp}$ is devoid of repair systems meaning the buildup of lesions. There are 37 genes located in mtDNA with those encoding protein subunits of complex I (7), complex II (1), and complex IV (3) but not complex III. Interestingly, hallmarks of AD (APP, A $\beta$, and NFTs) mostly affect members of electron transfer chain (complexes I and IV) which rely exclusively on mitochondrially predetermined subunits. Maybe it is not simple coincidence, but the effect of inhibited import to mitochondria of nuclearencoded subunits of complexes I and IV gives explanation for toxicity of APP or A $\beta$, or NFTs in mitochondria. There are additional findings in mitochondria affected by AD such as lower activity of pyruvate dehydrogenase (PDH) and oxoglutarate dehydrogenase (OGDH) [104, 132]. Inhibition of OGDH, the enzyme of tricarboxylic acid cycle, minimizes the NADH pool and electron number needed for ETC and mitochondrial membrane potential $\left(\Delta \psi_{m}\right)$ to create and maintain proton gradient obligatory for ATP synthesis. There are also lines of evidence for direct inhibitory action of soluble oligomeric $\mathrm{A} \beta$ species on $\mathrm{ABAD}$ ( $\mathrm{A} \beta$-binding alcohol dehydrogenase) and internal membrane cyclophilin $\mathrm{D}(\mathrm{CypD})$ resulting in increased mitochondrial membrane permeability (MPTP), potentiated ROS production, synaptic loss, diminished activity of mitochondrial respiration, and finally cell death [129, 132-134]. CypD knockout prevents mitochondrial and neuronal perturbations and improves mitochondrial function in Alzheimer's disease mouse model [128, 135]. It has to be emphasized that oxidative/nitrosative stress affects the fusion and fission process of mitochondria. Fusion, that is, speedup by small GTPases mitofusins (Mfn1/Mfn2), improves efficiency of mitochondrial respiration and ATP production. Mitochondrial dynamics are severely imbalanced in $\mathrm{AD}$ cases in favour of fission, through elevated expression of the fission protein DLP1 (dynamin-like protein 1) associated with nitrosative stress stirred up by $\mathrm{A} \beta[136,137]$. Collectively, these observations indicate that toxic intracellular $\mathrm{A} \beta_{42-43}$ oligomers differ in action from extracellular aggregates found in amyloid plaques of $\mathrm{AD}$ brains [138] (Figure 3).

\section{Proteostasis in Mitochondria}

Mitochondrial protein turnover grants the well-organized replacement of nonfunctional proteins into operational one. The first task is attained through proteolytic degradation of inner membrane and matrix proteins with local mitochondrial proteases [139] or outer membrane proteins through ubiquitin-proteasome system [140]. The second task is met by intramitochondrial protein synthesis but as almost 1500 different nuclear-encoded proteins have to be imported to complete mitochondrial proteome, a matter of capable import is fundamental for the function of the organelle. In extreme cases of cellular injuries observed in neurodegenerative diseases, damaged mitochondria with extended loss of the electrochemical potential are selectively removed by autophagy known as mitophagy [112]. APP and A $\beta$ accumulation has also something to do with altered mitochondrial dynamics as fission takes advantage of fusion with resultant dysfunction of mitochondria and neurons [137]. $\mathrm{AD}$ neurons demonstrated selective mechanisms of proteolytic clearance of oxidatively and nitrosatively modified proteins in mitochondria. Insulin degrading enzyme (IDE) prevents formation of toxic insoluble fibrils from $\mathrm{A} \beta$, as it cleaves $\mathrm{A} \beta$ prior to aggregation [141-143]. A novel zincmetallopeptidase, Presequence Protease (PreP), a member of pitrilysin oligopeptidase family, degrades either intramitochondrially stored $\mathrm{A} \beta_{40}$ or $\mathrm{A} \beta_{42}$ protein. This protease seems to be highly sensitive to oxidative stress, as disulfide bridge formed between two proximal cysteine residues blocks its catalytic activity [144-149]. Another mitochondrial serine protease HtrA2/Omi occupies intermembrane space where it can cleave APP locked up in protein translocase complex [121]. Even though it is well established that HtrA2/Omi is released to the cytosol to amplify apoptosis through the degradation of antiapoptotic proteins and caspase activation [150-152], it is also implicated in proteolytic deletion of malfolded APP in ER [151]. From knockout studies on mice, it is obvious that HtrA2/Omi plays a significant shielding role as mice deficient in this protease exhibit neurodegenerative phenotype with weight loss and premature death [153]. Taken together, understanding the mechanisms of clearance of the unwanted proteins including APP, $\mathrm{A} \beta$, and tau is vital in an attempt to get rid of them from mitochondria. 


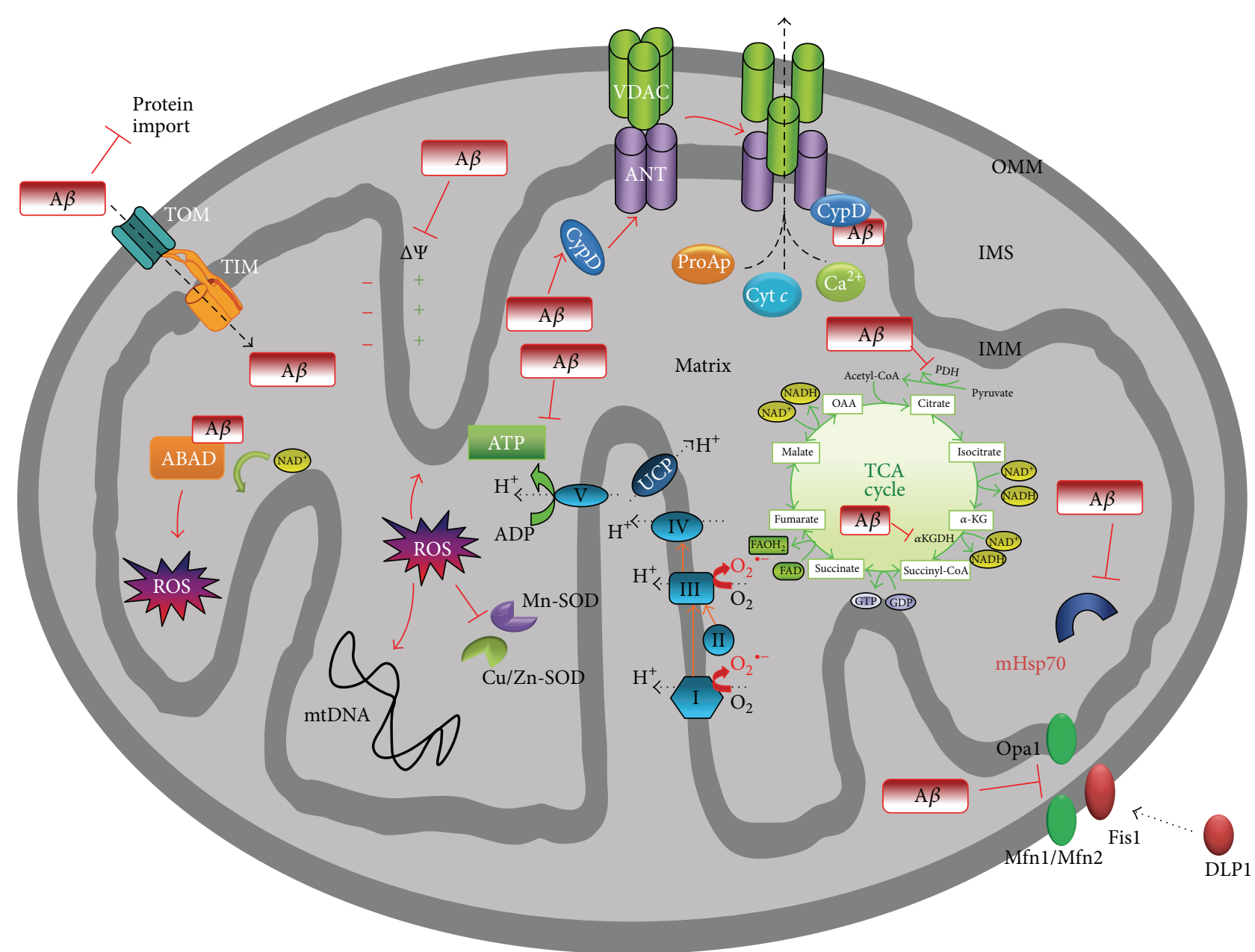

FIgURE 3: Amyloid- $\beta$-related mitochondrial impairment. Mitochondria were found to be the target for amyloid- $\beta$ (A $\beta$ ), which interacts with several proteins, leading to mitochondrial dysfunction. Indeed, $A \beta$ was found in the outer mitochondrial membrane (OMM) and inner mitochondrial membrane (IMM) as well as in the matrix. The interaction of $\mathrm{A} \beta$ with the OMM affects the transport of nuclearencoded mitochondrial proteins, such as subunits of the electron transport chain complex IV, into the organelle via the translocase of the outer membrane (TOM) import machinery. Moreover, $\mathrm{A} \beta$ disturbs the activity of several enzymes, such as pyruvate dehydrogenase (PDH) and oxoglutarate dehydrogenase (OGDH), decreasing NADH reduction, and the electron transport chain enzyme complex IV, reducing the amount of hydrogen that is translocated from the matrix to the intermembrane space (IMS), thus impairing the mitochondrial membrane potential (MMP). Taken together, these events cause abnormal mitochondrial electron activities, leading to decreased complex $\mathrm{V}$ activity and so to a drop in ATP levels, in addition to increasing reactive oxygen species (ROS) generation. Moreover, ROS induce peroxidation of several mitochondrial macromolecules, such as mitochondrial DNA (mtDNA) and mitochondrial lipids, contributing to mitochondrial impairment in the mitochondrial matrix. The complex of $A \beta$ bound to binding alcohol dehydrogenase (ABAD) impairs the binding of $N_{A D}{ }^{+}$ to $\mathrm{ABAD}$, changes mitochondrial membrane permeability, and reduces activities of respiratory enzymes, inducing further ROS production and leading to mitochondrial failure. $\mathrm{A} \beta$ binding also activates Fisl (fission protein) and promotes increased mitochondrial fragmentation; this increased mitochondrial fragmentation produces defective mitochondria that ultimately damage neurons. Furthermore, $A \beta$ binding to cyclophilin D (CypD) enhances the protein translocation to the inner membrane, favouring the opening of the mitochondrial permeability transition pore, formed by the adenine nucleotide translocator (ANT) and voltage-dependent anion channels (VDACs). Cyt $c$ : cytochrome $c$; DLP1: dynamin-like protein 1; PDH: pyruvate dehydrogenase; ProAp: proapoptotic factors; SOD: superoxide dismutase; TCA: tricarboxylic acid; TIM: translocase of the inner membrane. Adopted from [14].

Some hopes are associated with the application of at present indefinite modulators of proteolytic activity. HtrA2/Omi is, for example, activated by PTEN-induced putative kinase 1 (PINK1) upon phosphorylation at Ser142 residue [154]. Alternatively, accent has to be put on mitophagy of dysfunctional mitochondria and mitochondriogenesis.

\section{Aging versus AD}

The most common neurodegenerative disorder is represented by Alzheimer's disease, characterized by declining memory, reduced cognitive capacity, and progressive dementia, which are often fatal to elderly individuals above 65 years of age. 
It is ranked as the fourth leading cause of death in modern societies where average life span increased greatly in the last two decades. As $95 \%$ of AD cases are diagnosed in older people, one might think that a causal relationship exists between aging and the onset of disease. Certainly, a number of similarities between getting old and being affected with AD could be listed. Historically, the free radical theory of aging by Harman [155] suggested aging as "side effect" of reactive oxygen species formed in mitochondrial respiratory chain. Apparently, free radicals, commonly generated by incomplete reduction of oxygen molecule at complexes I and III of mitochondrial ETC, are capable of damaging DNA, RNA, and proteins. They impair energy storage and lead to operational failure of mitochondria with progressive decline of cell viability. Almost identical conditions accompany $\mathrm{AD}$ and are an explicit step in pathogenesis of disease. As mtDNA is deprived of repair mechanisms, ROS-induced DNA strand breaks tend to accumulate with age or AD. Thus, mtDNA is a vulnerable target for ROS, but the reverse, the ROS generation due to the mutated mtDNA, is not convincingly confirmed [156]. Moreover, the evidence that mutated mtDNA accelerates the progress of aging is also questioned based on the results from study carried out on transgenic mice model [157]. Although some authors show inconsistency between the free radical theory and observations, cumulative evaluation of the scientific reports points to antioxidant defense systems as important factors in protection from premature aging [158]. Other mitochondrial components important for their function are hampered with age: adenine nucleotide translocase (ANT), nitric oxide synthase (NOS), and carnitine acyltransferase (CT) [159-161]. Actually, NOS activity is elevated in AD as reported from study performed on cellular model of disease [15]. We could not find any information about CT activity in $\mathrm{AD}$, whereas ANT activity is noticeably inhibited by $\mathrm{A} \beta$ or hyperphosphorylated tau and this effect is reversed by mersalyl, a reversible alkylating agent of thiol groups [162]. Mitochondrial dysfunction, observed in transgenic mice models of $\mathrm{AD}$ and aging, demonstrates higher activity of genes controlling energy metabolism and apoptosis. Taken together, physiological aging and $\mathrm{AD}$ are associated with broad-spectrum dysfunction of mitochondria, but the foundations of mitochondrial decline are dissimilar. More discrepancies between physiological aging and $\mathrm{AD}$ were found with respect to ERS and UPR which play a significant role in cellular proteostasis. Dolichol was selected as an aging marker because the progressive increase in dolichol level was observed in aging brain [163]. In contrast, ubiquinone concentration which is also synthesized from geranylgeraniol diminishes with aging whereas cholesterol and dolichyl phosphate concentrations remain unaltered. In $\mathrm{AD}$, decreased levels of dolichol were observed and increased levels of ubiquinone and dolichyl phosphate without any changes in brain cholesterol. AD cannot be regarded as a result of premature aging. The drop in dolichol and augmented dolichyl phosphate concentration points toward disturbed glycosylation in ER of diseased brain, while the increase in ubiquinone suggests efforts to protect the brain from oxidative stress induced by lipid peroxidation $[164,165]$.

\section{Targeting ER Stress in AD Therapy}

As ERS is a recognized factor in $\mathrm{AD}$, drugs that interfere with ERS would theoretically have great therapeutic potential. There are several compounds grouped in classes that interact directly with components of the ERS (salubrinal, $\mathrm{BiP}$ inducer X (BIX), salicylamide analogs, flavonoids, guanabenz, and STF083010), chemical chaperons (4-phenylbutyric acid (PBA), tauroursodeoxycholic acid (TUDCA), and trimethylamine oxide (TMAO)), chemicals that inhibit protein degradation (Eeyarestatin, MG132, and Bortezomib), compounds with antioxidant activity (Edaravone, dibenzoylmethane derivatives, and N-acetyl cysteine (NAC)), and drugs controlling calcium signaling (dantrolene and carbazole derivatives) [166]. They may act by inducing transient translation arrest, upregulation of chaperone proteins, and augmented degradation of ER-associated misfolded proteins. Fundamental approach in the development of new therapy is the selection of appropriate molecular targets. In ER stress signaling, the aim is to alter the expression of ER stressassociated molecules that can rescue cells from the toxic effect of ERS. Recent efforts in establishing new promising drugs against $\mathrm{AD}$ are pointing to chemical chaperones such as PBA, TUDCA, or trimethylamine oxide (TMAO). These substances improve protein folding and alleviate native protein conformation [166]. It was shown on mouse models of $\mathrm{AD}$ that PBA, TUDCA, and TMAO stop A $\beta$ accumulation and avoid the loss of dendritic spines [167]. Some observations even demonstrated improved memory and cognitive functions [168] associated with improved cell survival [169]. Salubrinal ((2E)-3-phenyl- $N$-[2,2,2-trichloro-1-[[(8-quinolinylamino)thioxomethyl] amino] ethyl]-2-propenamide, Sal) selectively inhibits growth arrest and DNA damage induced gene 34- (GADD34-) phosphatase complex (GADD34 associates with protein phosphatase 1 (PP1)) and promotes in vitro dephosphorylation of the alpha subunit of eIF- $2 \alpha$ and IRE1 $\alpha / \mathrm{ASK} 1 / \mathrm{JNK}$ signaling pathway being protective against ERS even induced by tunicamycin Tm [170]. In a great deal of experiments testing Sal in cultured cells and animal models of $\mathrm{AD}$, this substance increased the viability of neuronal cells and $\mathrm{A} \beta$ toxicity $[171,172]$. BIX (2-(3,4-dihydroxyphenyl)2-oxoethyl ester thiocyanic acid) preferentially induced BiP mRNA in an ATF6-dependent manner leading to reduced Tm-induced death of neuronal cells [173]. Also DBM derivative 14-26 (2,2' -dimethoxydibenzoylmethane) was found to be neuroprotective for SH-SY5Y and PC-12 cells by decreasing expression of $\mathrm{BiP}$ and $\mathrm{CHOP}$ [174]. Dantrolene, a ryanodine receptor antagonist that inhibits abnormal calcium release from the ER, inhibited expression of both phosphorylated PERK and eIF $2 \alpha$. It also reduced $\mathrm{CHOP}$ expression and attenuated thapsigargin-induced apoptosis in PC-12 cells [175]. Neuroprotective effects similar to dantrolene were observed for ([9-(3-cyanobenzyl)-1,4dimethylcarbazole]). This substance suppressed increases in intracellular $\mathrm{Ca}^{2+}$ in PC-12 cells treated with thapsigargin and reduced levels of BiP and CHOP [176].

Aforementioned compounds were chosen from others as the most potent ER stress inhibitors and persuasively protective to neuronal cells. 18 of 42 different compounds 
were exploited in in vivo and in vitro models of central nervous system disorders with, in fact, improved cell or tissue viability [166]. Thus, the brain is the most frequently investigated organ in the context of ERS. From these experiments, it becomes clear that $\mathrm{CHOP}$ functions as proapoptotic factor. The roles of other specific ER stress molecules as molecular targets for pharmacological intervention are less clear and vary depending on cell type and context.

There are few underestimated modulations in APP processing that shed more light on current dogma of AD pathogenesis. The modulation of mevalonate pathway and cholesterol synthesis were reported to stimulate nonamyloidogenic pathway of APP processing [177]. Additionally, cholesterol derivative 27-hydroxycholesterol (27-OHC) was shown to induce ER stress which attenuated leptin-dependent viability by activating CHOP in SH-SY5Y neuroblastoma cells [178]. Irrespective of a number of compounds examined in $\mathrm{AD}$, the call for new drugs modulating ER stress with healing effect is still waiting to be revealed.

\section{Abbreviations}

\begin{tabular}{|c|c|}
\hline APOE: & Apolipoprotein E \\
\hline $\mathrm{APP}^{\mathrm{s}}:$ & Secreted form of APP \\
\hline CHOP/GADD153: & $\begin{array}{l}\text { C/EBP homologous protein/ } \\
\text { growth arrest and DNA damage } \\
\text { induced gene } 153\end{array}$ \\
\hline Drp1: & Dynamin-1-like protein \\
\hline ERAD: & $\begin{array}{l}\text { Endoplasmic-reticulum- } \\
\text { associated protein degradation }\end{array}$ \\
\hline ERO1 $\alpha$ : & ER oxidase $1 \alpha$ \\
\hline ERS: & Endoplasmic reticulum stress \\
\hline FOH: & Farnesol \\
\hline GGOH: & Geranylgeraniol \\
\hline GRP75: & Glucose-regulated protein 75 \\
\hline GRP78/BiP: & $78 \mathrm{kDa}$ glucose-regulated protein \\
\hline GSK-3 $\beta$ : & Synthase kinase 3 beta \\
\hline $\mathrm{IP}_{3} \mathrm{R}:$ & Inositol triphosphate receptor \\
\hline IRE1 $\alpha$ : & Inositol-requiring enzyme 1 alpha \\
\hline MAM: & $\begin{array}{l}\text { Mitochondria-associated } \\
\text { membrane }\end{array}$ \\
\hline MAP LC3: & $\begin{array}{l}\text { Microtubule-associated protein } \\
\text { light chain } 3\end{array}$ \\
\hline Mfn2: & GTPase mitofusin 2 \\
\hline MMP: & $\begin{array}{l}\text { Mitochondrial membrane } \\
\text { potential }\end{array}$ \\
\hline MPTP: & $\begin{array}{l}\text { Mitochondrial permeability } \\
\text { transition pore }\end{array}$ \\
\hline NFT: & Neurofibrillary tangles \\
\hline PACS-2: & $\begin{array}{l}\text { Phosphofurin acidic cluster } \\
\text { sorting protein } 2\end{array}$ \\
\hline PDI: & Protein disulfide isomerase \\
\hline PERK: & $\begin{array}{l}\text { Protein kinase R- (PKR-) like } \\
\text { ER kinase }\end{array}$ \\
\hline RNS: & Reactive nitrogen species \\
\hline ROS: & Reactive oxygen species \\
\hline RyR: & Ryanodine receptor \\
\hline TOM: & Transporter outer membrane \\
\hline TIM: & Transporter inner membrane \\
\hline
\end{tabular}

UPR: Unfolded protein response

VDAC: Voltage-dependent anion channel

XBP-1: Xbox binding protein 1 .

\section{Conflict of Interests}

The authors declare that there is no conflict of interests regarding the publication of this paper.

\section{Acknowledgment}

Support for this work was provided by Grant no. UMO2011/03/B/NZ7/0238 from the National Science Centre in Poland.

\section{References}

[1] R. L. Nussbaum and C. E. Ellis, "Alzheimer's disease and Parkinson's disease," The New England Journal of Medicine, vol. 348, no. 14, pp. 1356-1364, 2003.

[2] A. L. Brunkan and A. M. Goate, "Presenilin function and $\gamma$ secretase activity," The Journal of Neurochemistry, vol. 93, no. 4, pp. 769-792, 2005.

[3] V. Crentsil, “The pharmacogenomics of Alzheimer's disease," Ageing Research Reviews, vol. 3, no. 2, pp. 153-169, 2004.

[4] D. L. Price and S. S. Sisodia, "Mutant genes in familial Alzheimer's disease and transgenic models," Annual Review of Neuroscience, vol. 21, pp. 479-505, 1998.

[5] D. Harman, "Alzheimer's disease pathogenesis: role of aging," Annals of the New York Academy of Sciences, vol. 1067, no. 1, pp. 454-460, 2006.

[6] D. J. Selkoe, "Translating cell biology into therapeutic advances in Alzheimer's disease," Nature, vol. 399, pp. A23-A31, 1999.

[7] H. Braak and E. Braak, "Neuropathological stageing of Alzheimer-related changes," Acta Neuropathologica, vol. 82, no. 4, pp. 239-259, 1991.

[8] K. Hirai, G. Aliev, A. Nunomara et al., "Mitochondrial abnormalities in Alzheimer's disease," The Journal of Neuroscience, vol. 21, pp. 3017-3023, 2001.

[9] U. T. Brunk, C. B. Jones, and R. S. Sohal, "A novel hypothesis of lipofuscinogenesis and cellular aging based on interactions between oxidative stress and autophagocytosis," Mutation Research/DNAging, vol. 275, no. 3-6, pp. 395-403, 1992.

[10] P. A. Stewart, K. Hayakawa, M.-A. Akers, and H. V. Vinters, "A morphometric study of the blood-brain barrier in Alzheimer's disease," Laboratory Investigation, vol. 67, no. 6, pp. 734-742, 1992.

[11] J. P. Blass and G. E. Gibson, "The role of oxidative abnormalities in the pathophysiology of Alzheimer's disease," Revue Neurologique, vol. 147, no. 6-7, pp. 513-525, 1991.

[12] B. Pająk, E. Kania, and A. Orzechowski, "Nucleofection of rat pheochromocytoma PC-12 cells with human mutated betaamyloid precursor protein gene $(A P P-s w)$ leads to reduced reduced viability, autophagy-like process, and increased expression and secretion of beta amyloid," BioMed Research International, vol. 2015, Article ID 746092, 10 pages, 2015.

[13] J. P. Blass, "Cerebrometabolic abnormalities in Alzheimer's disease," Neurological Research, vol. 25, no. 6, pp. 556-566, 2003. 
[14] A. Eckert, K. Schmitt, and J. Götz, "Mitochondrial dysfunction-the beginning of the end in Alzheimer's disease? Separate and synergistic modes of tau and amyloid- $\beta$ toxicity," Alzheimer's Research \& Therapy, vol. 3, article 15, pp. 1-11, 2011.

[15] U. Keil, A. Bonert, C. A. Marques et al., "Amyloid $\beta$-induced changes in nitric oxide production and mitochondrial activity lead to apoptosis," The Journal of Biological Chemistry, vol. 279, no. 48, pp. 50310-50320, 2004.

[16] A. M. Swomley and D. A. Butterfield, "Oxidative stress in Alzheimer disease and mild cognitive impairment: evidence from human data provided by redox proteomics," Archives of Toxicology, vol. 89, no. 10, pp. 1669-1680, 2015.

[17] C. Caspersen, N. Wang, J. Yao et al., "Mitochondrial A $\beta$ : a potential focal point for neuronal metabolic dysfunction in Alzheimer's disease," The FASEB Journal, vol. 19, no. 14, pp. 2040-2041, 2005.

[18] G. E. Gibson, K.-F. R. Sheu, and J. P. Blass, "Abnormalities of mitochondrial enzymes in Alzheimer disease," Journal of Neural Transmission, vol. 105, no. 8-9, pp. 855-870, 1998.

[19] A. Eckert, S. Hauptmann, I. Scherping et al., "Soluble betaamyloid leads to mitochondrial defects in amyloid precursor protein and tau transgenic mice," Neurodegenerative Diseases, vol. 5, no. 3-4, pp. 157-159, 2008.

[20] A. Eckert, K. L. Schulz, V. Rhein, and J. Götz, "Convergence of amyloid- $\beta$ and tau pathologies on mitochondria in vivo," Molecular Neurobiology, vol. 41, no. 2-3, pp. 107-114, 2010.

[21] S. Hauptmann, I. Scherping, S. Dröse et al., "Mitochondrial dysfunction: an early event in Alzheimer pathology accumulates with age in AD transgenic mice," Neurobiology of Aging, vol. 30, no. 10, pp. 1574-1586, 2009.

[22] M. Manczak, B. S. Park, Y. Jung, and P. H. Reddy, "Differential expression of oxidative phosphorylation genes in patients with Alzheimer's disease: implications for early mitochondrial dysfunction and oxidative damage," NeuroMolecular Medicine, vol. 5, no. 2, pp. 147-162, 2004.

[23] M. P. Mattson, M. Gleichmann, and A. Cheng, "Mitochondria in neuroplasticity and neurological disorders," Neuron, vol. 60, no. 5, pp. 748-766, 2008.

[24] P. I. Moreira, M. S. Santos, and C. R. Oliveira, "Alzheimer's disease: a lesson from mitochondrial dysfunction," Antioxidants \& Redox Signaling, vol. 9, no. 10, pp. 1621-1630, 2007.

[25] P. H. Reddy, "Mitochondrial dysfunction in aging and Alzheimer's disease: strategies to protect neurons," Antioxidants \& Redox Signaling, vol. 9, no. 10, pp. 1647-1658, 2007.

[26] V. Rhein, G. Baysang, S. Rao et al., "Amyloid-beta leads to impaired cellular respiration, energy production and mitochondrial electron chain complex activities in human neuroblastoma cells," Cellular and Molecular Neurobiology, vol. 29, no. 6-7, pp. 1063-1071, 2009.

[27] V. Rhein, X. Song, A. Wiesner et al., "Amyloid- $\beta$ and tau synergistically impair the oxidative phosphorylation system in triple transgenic Alzheimer's disease mice," Proceedings of the National Academy of Sciences of the United States of America, vol. 106, no. 47, pp. 20057-20062, 2009.

[28] R. X. Santos, S. C. Correia, X. Wang et al., "Alzheimer's disease: diverse aspects of mitochondrial malfunctioning," International Journal of Clinical and Experimental Pathology, vol. 3, no. 6, pp. 570-581, 2010.

[29] N. R. Sims, "Energy metabolism, oxidative stress and neuronal degeneration in Alzheimer's disease," Neurodegeneration, vol. 5, no. 4, pp. 435-440, 1996.
[30] H. K. Anandatheerthavarada, G. Biswas, M.-A. Robin, and N. G. Avadhani, "Mitochondrial targeting and a novel transmembrane arrest of Alzheimer's amyloid precursor protein impairs mitochondrial function in neuronal cells," The Journal of Cell Biology, vol. 161, no. 1, pp. 41-54, 2003.

[31] L. Devi, B. M. Prabhu, D. F. Galati, N. G. Avadhani, and H. K. Anandatheerthavarada, "Accumulation of amyloid precursor protein in the mitochondrial import channels of human Alzheimer's disease brain is associated with mitochondrial dysfunction," The Journal of Neuroscience, vol. 26, no. 35, pp. 9057-9068, 2006.

[32] L. Devi and H. K. Anandatheerthavarada, "Mitochondrial trafficking of APP and alpha synuclein: relevance to mitochondrial dysfunction in Alzheimer's and Parkinson's diseases," Biochimica et Biophysica Acta, vol. 1802, no. 1, pp. 11-19, 2010.

[33] M. Manczak, T. S. Anekonda, E. Henson, B. S. Park, J. Quinn, and P. H. Reddy, "Mitochondria are a direct site of A $\beta$ accumulation in Alzheimer's disease neurons: implications for free radical generation and oxidative damage in disease progression," Human Molecular Genetics, vol. 15, no. 9, pp. 1437-1449, 2006.

[34] P. F. Pavlov, C. H. Petersen, E. Glaser, and M. Ankarcrona, "Mitochondrial accumulation of APP and A $\beta$ : significance for Alzheimer disease pathogenesis," Journal of Cellular and Molecular Medicine, vol. 13, no. 10, pp. 4137-4145, 2009.

[35] C. Schmidt, E. Lepsverdize, S. L. Chi et al., "Amyloid precursor protein and amyloid $\beta$-peptide bind to ATP synthase and regulate its activity at the surface of neural cells," Molecular Psychiatry, vol. 13, no. 10, pp. 953-969, 2008.

[36] K. Johar, A. Priya, and M. T. T. Wong-Riley, "Regulation of $\mathrm{Na}^{+} / \mathrm{K}^{+}$-ATPase by nuclear respiratory factor 1 : implication in the tight coupling of neuronal activity, energy generation, and energy consumption," The Journal of Biological Chemistry, vol. 287, no. 48, pp. 40381-40390, 2012.

[37] J. Astrup, P. M. Sorensen, and H. R. Sorensen, "Oxygen and glucose consumption related to $\mathrm{Na}^{+}-\mathrm{K}^{+}$transport in canine brain," Stroke, vol. 12, no. 6, pp. 726-730, 1981.

[38] M. Erecinska and I. A. Silver, "ATP and brain function," Journal of Cerebral Blood Flow and Metabolism, vol. 9, no. 1, pp. 2-19, 1989.

[39] M. Mata, D. J. Fink, H. Gainer et al., "Activity-dependent energy metabolism in rat posterior pituitary primarily reflects sodium pump activity," Journal of Neurochemistry, vol. 34, no. 1, pp. 213215,1980

[40] J. Kang, H.-G. Lemaire, A. Unterbeck et al., "The precursor of Alzheimer's disease amyloid A4 protein resembles a cell-surface receptor," Nature, vol. 325, no. 6106, pp. 733-736, 1987.

[41] C. L. Masters and D. J. Selkoe, "Biochemistry of amyloid $\beta$ protein and amyloid deposits in Alzheimer disease," Cold Spring Harbour Perspectives in Medicine, vol. 2, no. 6, Article ID a006262, 2012.

[42] A. Lai, S. S. Sisodia, and I. S. Trowbridge, "Characterization of sorting signals in the beta-amyloid precursor protein cytoplasmic domain," The Journal of Biological Chemistry, vol. 270, no. 8, pp. 3565-3573, 1995.

[43] A. I. Plácido, C. M. F. Pereira, A. I. Duarte et al., "The role of endoplasmic reticulum in amyloid precursor protein processing and trafficking: implications for Alzheimer's disease," Biochimica et Biophysica Acta-Molecular Basis of Disease, vol. 1842, no. 9, pp. 1444-1453, 2014. 
[44] C. Kaether, P. Skehel, and C. G. Dotti, "Axonal membrane proteins are transported in distinct carriers: a two-color video microscopy study in cultured hippocampal neurons," Molecular Biology of the Cell, vol. 11, no. 4, pp. 1213-1224, 2000.

[45] A. Kamal, A. Almenar-Queralt, J. F. LeBlanc, E. A. Roberts, and L. S. B. Goldstein, "Kinesin-mediated axonal transport of a membrane compartment containing $\beta$-secretase and presenilin-1 requires APP," Nature, vol. 414, no. 6864, pp. 643648, 2001.

[46] R. G. Perez, S. Soriano, J. D. Hayes et al., "Mutagenesis identifies new signals for $\beta$-amyloid precursor protein endocytosis, turnover, and the generation of secreted fragments, including A $\beta 42$," The Journal of Biological Chemistry, vol. 274, no. 27, pp. 18851-18856, 1999.

[47] D. G. Cook, M. S. Forman, J. C. Sung et al., "Alzheimer's A $\beta(1-$ 42 ) is generated in the endoplasmic reticulum/intermediate compartment of NT2N cells," Nature Medicine, vol. 3, no. 9, pp. 1021-1023, 1997.

[48] A. S. C. Chyung, B. D. Greenberg, D. G. Cook, R. W. Doms, and V. M.-Y. Lee, "Novel $\beta$-secretase cleavage of $\beta$-amyloid precursor protein in the endoplasmic reticulum/intermediate compartment of NT2N cells," The Journal of Cell Biology, vol. 138, no. 3, pp. 671-680, 1997.

[49] R. W.-Y. Choy, Z. Cheng, and R. Schekman, "Amyloid precursor protein (APP) traffics from the cell surface via endosomes for amyloid $\beta(\mathrm{A} \beta)$ production in the trans-Golgi network," Proceedings of the National Academy of Sciences of the United States of America, vol. 109, no. 30, pp. E2077-E2082, 2012.

[50] S. A. Small and S. Gandy, "Sorting through the cell biology of Alzheimer's disease: intracellular pathways to pathogenesis," Neuron, vol. 52, no. 1, pp. 15-31, 2006.

[51] M. Goedert, "Alzheimer's and Parkinson's diseases: the prion concept in relation to assembled $\mathrm{A} \beta$, tau, and $\alpha$-synuclein," Science, vol. 349, no. 6248, 2015.

[52] I. Benilova, E. Karran, and B. De Strooper, "The toxic A $\beta$ oligomer and Alzheimer's disease: an emperor in need of clothes," Nature Neuroscience, vol. 15, no. 3, pp. 349-357, 2012.

[53] E. H. Corder, A. M. Saunders, W. J. Strittmatter et al., "Gene dose of apolipoprotein E type 4 allele and the risk of Alzheimer's disease in late onset families," Science, vol. 261, no. 5123, pp. 921923, 1993.

[54] S. Brunholz, S. Sisodia, A. Lorenzo, C. Deyts, S. Kins, and G. Morfini, "Axonal transport of APP and the spatial regulation of APP cleavage and function in neuronal cells," Experimental Brain Research, vol. 217, no. 3-4, pp. 353-364, 2012.

[55] G. Thinakaran and E. H. Koo, "Amyloid precursor protein trafficking, processing, and function," The Journal of Biological Chemistry, vol. 283, no. 44, pp. 29615-29619, 2008.

[56] T. Saitoh, M. Sundsmo, J.-M. Roch et al., "Secreted form of amyloid beta protein precursor is involved in the growth regulation of fibroblasts," Cell, vol. 58, no. 4, pp. 615-622, 1989.

[57] M. P. Mattson, B. Cheng, A. R. Culwell, F. S. Esch, I. Lieberburg, and R. E. Rydel, "Evidence for excitoprotective and intraneuronal calcium-regulating roles for secreted forms of the $\beta$ amyloid precursor protein," Neuron, vol. 10, no. 2, pp. 243-254, 1993.

[58] K. J. Lee, C. E. H. Moussa, Y. Lee et al., "Beta amyloidindependent role of amyloid precursor protein in generation and maintenance of dendritic spines," Neuroscience, vol. 169, no. 1, pp. 344-356, 2010.
[59] H. Meziane, J.-C. Dodart, C. Mathis et al., "Memory-enhancing effects of secreted forms of the $\beta$-amyloid precursor protein in normal and amnestic mice," Proceedings of the National Academy of Sciences of the United States of America, vol. 95, no. 21, pp. 12683-12688, 1998.

[60] P. R. Turner, K. O'Connor, W. P. Tate, and W. C. Abraham, "Roles of amyloid precursor protein and its fragments in regulating neural activity, plasticity and memory," Progress in Neurobiology, vol. 70, no. 1, pp. 1-32, 2003.

[61] D. Beher, L. Hesse, C. L. Masters, and G. Multhaup, "Regulation of Amyloid Protein Precursor (APP) binding to collagen and mapping of the binding sites on APP and collagen type I," The Journal of Biological Chemistry, vol. 271, no. 3, pp. 1613-1620, 1996.

[62] S. L. Sabo, A. F. Ikin, J. D. Buxbaum, and P. Greengard, "The amyloid precursor protein and its regulatory protein, FE65, in growth cones and synapses in vitro and in vivo," The Journal of Neuroscience, vol. 23, no. 13, pp. 5407-5415, 2003.

[63] D. H. Small, V. Nurcombe, G. Reed et al., "A heparin-binding domain in the amyloid protein precursor of Alzheimer's disease is involved in the regulation of neurite outgrowth," The Journal of Neuroscience, vol. 14, no. 4, pp. 2117-2127, 1994.

[64] T. G. Williamson, S. S. Mok, A. Henry et al., "Secreted glypican binds to the amyloid precursor protein of Alzheimer's disease (APP) and inhibits APP-induced neurite outgrowth," The Journal of Biological Chemistry, vol. 271, no. 49, pp. 31215-31221, 1996.

[65] T. Ondrejcak, I. Klyubin, N.-W. Hu, A. E. Barry, W. K. Cullen, and M. J. Rowan, "Alzheimer's disease amyloid $\beta$-protein and synaptic function," NeuroMolecular Medicine, vol. 12, no. 1, pp. 13-26, 2010.

[66] D. Puzzo, L. Privitera, and A. Palmeri, "Hormetic effect of amyloid-beta peptide in synaptic plasticity and memory," Neurobiology of Aging, vol. 33, no. 7, pp. 1484.e15-1484.e24, 2012.

[67] C. M. F. Pereira, "Crosstalk between endoplasmic reticulum stress and protein misfolding in neurodegenerative diseases," ISRN Cell Biology, vol. 2013, Article ID 256404, 22 pages, 2013.

[68] R.-W. Shin, T. C. Saido, M. Maeda, and T. Kitamoto, "Novel $\alpha$ secretase cleavage of Alzheimer's amyloid $\beta$ precursor protein in the endoplasmic reticulum of COS7 cells," Neuroscience Letters, vol. 376, no. 1, pp. 14-19, 2005.

[69] E. A. Schon and E. Area-Gomez, "Mitochondria-associated ER membranes in Alzheimer disease," Molecular and Cellular Neuroscience, vol. 55, pp. 26-36, 2013.

[70] R. Rizzuto, P. Pinton, W. Carrington et al., "Close contacts with the endoplasmic reticulum as determinants of mitochondrial $\mathrm{Ca}^{2+}$ responses," Science, vol. 280, no. 5370, pp. 1763-1766, 1998.

[71] S. E. Logue, P. Cleary, S. Saveljeva, and A. Samali, "New directions in ER-stress induced cell death," Apoptosis, vol. 18, no. 5, pp. 537-546, 2013.

[72] J. P. Decuypere, K. Welkenhuyzen, T. Luyten et al., "Ins $(1,4,5) \mathrm{P} 3$ receptor-mediated $\mathrm{BI}-1 \mathrm{Ca}^{2+}$ signaling and autophagy induction are interrelated," Autophagy, vol. 7, pp. 1472-1489, 2011.

[73] K. S. Vetrivel and G. Thinakaran, "Membrane rafts in Alzheimer's disease beta-amyloid production," Biochimica et Biophysica Acta, vol. 1801, no. 8, pp. 860-867, 2010.

[74] H. Urra, E. Dufey, F. Lisbona, D. Rojas-Rivera, and C. Hetz, "When ER stress reaches a dead end," Biochimica et Biophysica Acta (BBA): Molecular Cell Research, vol. 1833, no. 12, pp. 35073517, 2013. 
[75] G. Li, M. Mongillo, K.-T. Chin et al., "Role of ERO1- $\alpha$-mediated stimulation of inositol 1,4,5-triphosphate receptor activity in endoplasmic reticulum stress-induced apoptosis," The Journal of Cell Biology, vol. 186, no. 6, pp. 783-792, 2009.

[76] K. Yamamoto, R. Fujii, Y. Toyofuku et al., "The KDEL receptor mediates a retrieval mechanism that contributes to quality control at the endoplasmic reticulum," The EMBO Journal, vol. 20, no. 12, pp. 3082-3091, 2001.

[77] T. Katayama, K. Imaizumi, N. Sato et al., "Presenilin-1 mutations downregulate the signalling pathway of the unfolded-protein response," Nature Cell Biology, vol. 1, no. 8, pp. 479-485, 1999.

[78] C. Ballatore, V. M.-Y. Lee, and J. Q. Trojanowski, “Tau-mediated neurodegeneration in Alzheimer's disease and related disorders," Nature Reviews Neuroscience, vol. 8, no. 9, pp. 663-672, 2007.

[79] B. Frost, R. L. Jacks, and M. I. Diamond, "Propagation of Tau misfolding from the outside to the inside of a cell," The Journal of Biological Chemistry, vol. 284, no. 19, pp. 12845-12852, 2009.

[80] T. Nonaka, S. T. Watanabe, T. Iwatsubo, and M. Hasegawa, "Seeded aggregation and toxicity of $\alpha$-synuclein and tau: cellular models of neurodegenerative diseases," Journal of Biological Chemistry, vol. 285, no. 45, pp. 34885-34898, 2010.

[81] J. F. Crary, J. Q. Trojanowski, J. A. Schneider et al., "Primary agerelated tauopathy (PART): a common pathology associated with human aging," Acta Neuropathologica, vol. 128, no. 6, pp. 755766, 2014.

[82] C. R. Jack Jr., D. S. Knopman, W. J. Jagust et al., “Tracking pathophysiological processes in Alzheimer's disease: an updated hypothetical model of dynamic biomarkers," The Lancet Neurology, vol. 12, no. 2, pp. 207-216, 2013.

[83] A. Serrano-Pozo, M. P. Frosch, E. Masliah, and B. T. Hyman, "Neuropathological alterations in Alzheimer disease," Cold Spring Harbor Perspectives in Medicine, vol. 1, no. 1, pp. 1-23, 2011.

[84] E. Ferreiro and C. M. F. Pereira, "Endoplasmic reticulum stress: a new playER in tauopathies," Journal of Pathology, vol. 226, no. 5, pp. 687-692, 2012.

[85] J. J. M. Hoozemans and W. Scheper, "Endoplasmic reticulum: the unfolded protein response is tangled in neurodegeneration," International Journal of Biochemistry \& Cell Biology, vol. 44, no. 8, pp. 1295-1298, 2012.

[86] J. J. M. Hoozemans, E. S. van Haastert, D. A. T. Nijholt, A. J. M. Rozemuller, P. Eikelenboom, and W. Scheper, "The unfolded protein response is activated in pretangle neurons in alzheimer's disease hippocampus," The American Journal of Pathology, vol. 174, no. 4, pp. 1241-1251, 2009.

[87] Y.-S. Ho, X. Yang, J. C.-F. Lau et al., "Endoplasmic reticulum stress induces tau pathology and forms a vicious cycle: implication in Alzheimer's disease pathogenesis," Journal of Alzheimer's Disease, vol. 28, no. 4, pp. 839-854, 2012.

[88] Z.-Q. Fu, Y. Yang, J. Song et al., " $\mathrm{LiCl}$ attenuates thapsigargininduced tau hyperphosphorylation by inhibiting GSK-3 $\beta$ in vivo and in vitro," Journal of Alzheimer's Disease, vol. 21, no. 4 , pp. 1107-1117, 2010.

[89] B. Schenk, F. Fernandez, and C. J. Waechter, "The ins(die) and out(side) of dolichyl phosphate biosynthesis and recycling in the endoplasmic reticulum," Glycobiology, vol. 11, pp. 61R-67R, 2001.

[90] A. Helenius and M. Aebi, "Intracellular functions of N-linked glycans," Science, vol. 291, no. 5512, pp. 2364-2369, 2001.
[91] J. Hitomi, T. Katayama, Y. Eguchi et al., "Involvement of caspase- 4 in endoplasmic reticulum stress-induced apoptosis and A $\beta$-induced cell death," The Journal of Cell Biology, vol. 165, no. 3, pp. 347-356, 2004.

[92] N. Morishima, K. Nakanishi, H. Takenouchi, T. Shibata, and Y. Yasuhiko, "An endoplasmic reticulum stress-specific caspase cascade in apoptosis. Cytochrome $c$-independent activation of caspase- 9 by caspase-12," The Journal of Biological Chemistry, vol. 277, no. 37, pp. 34287-34294, 2002.

[93] D. Rodriguez, D. Rojas-Rivera, and C. Hetz, "Integrating stress signals at the endoplasmic reticulum: the BCL-2 protein family rheostat," Biochimica et Biophysica Acta, vol. 1813, no. 4, pp. 564574, 2011.

[94] S. Y. Gilady, M. Bui, E. M. Lynes et al., "Erol $\alpha$ requires oxidizing and normoxic conditions to localize to the mitochondriaassociated membrane (MAM)," Cell Stress and Chaperones, vol. 15, no. 5, pp. 619-629, 2010.

[95] S. Wang and W. S. El-Deiry, "Cytochrome c: a crosslink between the mitochondria and the endoplasmic reticulum in calciumdependent apoptosis," Cancer Biology and Therapy, vol. 3, no. 1, pp. 44-46, 2004.

[96] I. Tabas and D. Ron, "Integrating the mechanisms of apoptosis induced by endoplasmic reticulum stress," Nature Cell Biology, vol. 13, no. 3, pp. 184-190, 2011.

[97] T. Yoneda, K. Imaizumi, K. Oono et al., "Activation of Caspase12 , an endoplastic reticulum (ER) resident caspase, through tumor necrosis factor receptor-associated factor 2-dependent mechanism in response to the ER stress," The Journal of Biological Chemistry, vol. 276, no. 17, pp. 13935-13940, 2001.

[98] A. Ebneth, G. Drewes, E.-M. Mandelkow, and E. Mandelkow, "Phosphorylation of MAP2c and MAP4 by MARK kinases leads to the destabilization of microtubules in cells," Cell Motility and the Cytoskeleton, vol. 44, no. 3, pp. 209-224, 1999.

[99] J. Götz, L. M. Ittner, M. Fändrich, and N. Schonrock, "Is tau aggregation toxic or protective: a sensible question in the absence of sensitive methods?" Journal of Alzheimer's Disease, vol. 14, no. 4, pp. 423-429, 2008.

[100] L. M. Ittner, Y. D. Ke, F. Delerue et al., "Dendritic function of tau mediates amyloid- $\beta$ toxicity in Alzheimer's disease mouse models," Cell, vol. 142, no. 3, pp. 387-397, 2010.

[101] K. Stamer, R. Vogel, E. Thies, E. Mandelkow, and E.-M. Mandelkow, "Tau blocks traffic of organelles, neurofilaments, and APP vesicles in neurons and enhances oxidative stress," The Journal of Cell Biology, vol. 156, no. 6, pp. 1051-1063, 2002.

[102] C. S. Casley, L. Canevari, J. M. Land, J. B. Clark, and M. A. Sharpe, " $\beta$-Amyloid inhibits integrated mitochondrial respiration and key enzyme activities," Journal of Neurochemistry, vol. 80, no. 1, pp. 91-100, 2002.

[103] C. S. Casley, J. M. Land, M. A. Sharpe, J. B. Clark, M. R. Duchen, and L. Canevari, " $\beta$-Amyloid fragment $25-35$ causes mitochondrial dysfunction in primary cortical neurons," Neurobiology of Disease, vol. 10, no. 3, pp. 258-267, 2002.

[104] S. Sorbi, E. D. Bird, and J. P. Blass, "Decreased pyruvate dehydrogenase complex activity in Huntington and Alzheimer brain," Annals of Neurology, vol. 13, no. 1, pp. 72-78, 1983.

[105] K. Takahashi, T. Niidome, A. Akaike, T. Kihara, and H. Sugimoto, "Amyloid precursor protein promotes endoplasmic reticulum stress-induced cell death via C/EBP homologous proteinmediated pathway," Journal of Neurochemistry, vol. 109, no. 5, pp. 1324-1337, 2009. 
[106] D. Kögel, C. G. Concannon, T. Müller et al., "The APP intracellular domain (AICD) potentiates ER stress-induced apoptosis," Neurobiology of Aging, vol. 33, no. 9, pp. 2200-2209, 2012.

[107] C. A. Hansson Petersen, N. Alikhani, H. Behbahani et al., "The amyloid $\beta$-peptide is imported into mitochondria via the TOM import machinery and localized to mitochondrial cristae," Proceedings of the National Academy of Sciences of the United States of America, vol. 105, no. 35, pp. 13145-13150, 2008.

[108] H. K. Anandatheerthavarada, N. B. V. Sepuri, G. Biswas, and N. G. Avadhani, "An unusual TOM20/TOM22 bypass mechanism for the mitochondrial targeting of cytochrome $\mathrm{P} 450$ proteins containing n-terminal chimeric signals," The Journal of Biological Chemistry, vol. 283, no. 28, pp. 19769-19780, 2008.

[109] M.-A. Robin, H. K. Anandatheerthavarada, G. Biswas et al., "Bimodal targeting of microsomal CYP2E1 to mitochondria through activation of an $\mathrm{N}$-terminal chimeric signal by cAMPmediated phosphorylation," The Journal of Biological Chemistry, vol. 277, no. 43, pp. 40583-40593, 2002.

[110] J. Zha, H. Harada, E. Yang, J. Jockel, and S. J. Korsmeyer, "Serine phosphorylation of death agonist BAD in response to survival factor results in binding to 14-3-3 not BCL-X(L)," Cell, vol. 87, no. 4, pp. 619-628, 1996.

[111] C. A. Hansson, S. Frykman, and M. R. Farmery, "Nicastrin, presenilin, APH-1, and PEN-2 form active gamma-secretase complexes in mitochondria," The Journal of Biological Chemistry, vol. 279, pp. 51654-51660, 2004.

[112] D. Narendra, A. Tanaka, D.-F. Suen, and R. J. Youle, "Parkin is recruited selectively to impaired mitochondria and promotes their autophagy," The Journal of Cell Biology, vol. 183, no. 5, pp. 795-803, 2008.

[113] A. Nechushtan, C. L. Smith, Y.-T. Hsu, and R. J. Youle, "Conformation of the Bax C-terminus regulates subcellular location and cell death," The EMBO Journal, vol. 18, no. 9, pp. 2330-2341, 1999.

[114] M. Suzuki, R. J. Youle, and N. Tjandra, "Structure of bax: coregulation of dimer formation and intracellular localization," Cell, vol. 103, no. 4, pp. 645-654, 2000.

[115] B. Y. Sheng, Y. Niu, H. Zhou et al., "The mitochondrial function was impaired in APP knockout mouse embryo fibroblast cells," Chinese Science Bulletin, vol. 54, no. 10, pp. 1725-1731, 2009.

[116] K. Chandrasekaran, K. Hatanpää, D. R. Brady, J. Stoll, and S. I. Rapoport, "Down regulation of oxidative phosphorylation in Alzheimer disease: loss of cytochrome oxidase subunit mRNA in the hippocampus and entorhinal cortex," Brain Research, vol. 796, no. 1-2, pp. 13-19, 1998.

[117] I. Maurer, S. Zierz, and H.-J. Möller, "A selective defect of cytochrome c oxidase is present in brain of Alzheimer disease patients," Neurobiology of Aging, vol. 21, no. 3, pp. 455-462, 2000.

[118] W. D. Parker Jr., "Cytochrome oxidase deficiency in Alzheimer's disease," Annals of the New York Academy of Sciences, vol. 640, pp. 59-64, 1991.

[119] W. D. Parker Jr., N. J. Mahr, C. M. Filley et al., "Reduced platelet cytochrome c oxidase activity in Alzheimer's disease," Neurology, vol. 44, no. 6, pp. 1086-1090, 1994.

[120] H. K. Anandatheerthavarada and L. Devi, "Mitochondrial translocation of amyloid precursor protein and its cleaved products: relevance to mitochondrial dysfunction in Alzheimer's disease," Reviews in the Neurosciences, vol. 18, no. 5, pp. 343-354, 2007.
[121] H.-J. Park, S.-S. Kim, Y.-M. Seong et al., “ $\beta$-Amyloid precursor protein is a direct cleavage target of HtrA2 serine protease: implications for the physiological function of HtrA2 in the mitochondria," The Journal of Biological Chemistry, vol. 281, no. 45, pp. 34277-34287, 2006.

[122] X. Wang, B. Su, S. L. Siedlak et al., "Amyloid- $\beta$ overproduction causes abnormal mitochondrial dynamics via differential modulation of mitochondrial fission/fusion proteins," Proceedings of the National Academy of Sciences of the United States of America, vol. 105, no. 49, pp. 19318-19323, 2008.

[123] D. C. David, S. Hauptmann, I. Scherping et al., "Proteomic and functional analyses reveal a mitochondrial dysfunction in P301L tau transgenic mice," The Journal of Biological Chemistry, vol. 280, no. 25, pp. 23802-23814, 2005.

[124] D. C. David, L. M. Ittner, P. Gehrig et al., “ $\beta$-Amyloid treatment of two complementary P301L tau-expressing Alzheimer's disease models reveals similar deregulated cellular processes," Proteomics, vol. 6, no. 24, pp. 6566-6577, 2006.

[125] S. M. Cardoso, M. T. Proenca, S. Santos, I. Santana, and C. R. Oliveira, "Cytochrome coxidase is decreased in Alzheimer's disease platelets," Neurobiology of Aging, vol. 25, pp. 105-110, 2004.

[126] S. J. Kish, C. Bergeron, A. Rajput et al., "Brain cytochrome oxidase in Alzheimer's disease," Journal of Neurochemistry, vol. 59, no. 2, pp. 776-779, 1992.

[127] P. J. Crouch, R. Blake, J. A. Duce et al., "Copper-dependent inhibition of human cytochrome $c$ oxidase by a dimeric conformer of amyloid- $\beta 1-42$," The Journal of Neuroscience, vol. 25, no. 3, pp. 672-679, 2005.

[128] H. Du, L. Guo, F. Fang et al., "Cyclophilin D deficiency attenuates mitochondrial and neuronal perturbation and ameliorates learning and memory in Alzheimer's disease," Nature Medicine, vol. 14, no. 10, pp. 1097-1105, 2008.

[129] J. W. Lustbader, M. Cirilli, C. Lin et al., "ABAD directly links A $\beta$ to mitochondrial toxicity in Alzheimer's disease," Science, vol. 304, no. 5669, pp. 448-452, 2004.

[130] D. Sirk, Z. Zhu, J. S. Wadia et al., "Chronic exposure to sub-lethal beta-amyloid $(\mathrm{A} \beta)$ inhibits the import of nuclear-encoded proteins to mitochondria in differentiated PC12 cells," Journal of Neurochemistry, vol. 103, no. 5, pp. 1989-2003, 2007.

[131] S. Melov, P. A. Adlard, K. Morten et al., "Mitochondrial oxidative stress causes hyperphosphorylation of tau," PLOS ONE, vol. 2, no. 6, article e536, 2007.

[132] P. Bubber, V. Haroutunian, G. Fisch, J. P. Blass, and G. E. Gibson, "Mitochondrial abnormalities in Alzheimer brain: mechanistic implications," Annals of Neurology, vol. 57, no. 5, pp. 695-703, 2005.

[133] H. Du and S. S. Yan, "Mitochondrial permeability transition pore in Alzheimer's disease: cyclophilin D and amyloid beta," Biochimica et Biophysica Acta (BBA): Molecular Basis of Disease, vol. 1802, no. 1, pp. 198-204, 2010.

[134] J. Yao, M. Taylor, F. Davey et al., "Interaction of amyloid binding alcohol dehydrogenase/ $\mathrm{A} \beta$ mediates up-regulation of peroxiredoxin II in the brains of Alzheimer's disease patients and a transgenic Alzheimer's disease mouse model," Molecular and Cellular Neuroscience, vol. 35, no. 2, pp. 377-382, 2007.

[135] H. Du, L. Guo, W. Zhang, M. Rydzewska, and S. Yan, "Cyclophilin D deficiency improves mitochondrial function and learning/memory in aging Alzheimer disease mouse model," Neurobiology of Aging, vol. 32, no. 3, pp. 398-406, 2011. 
[136] D.-H. Cho, T. Nakamura, J. Fang et al., "S-nitrosylation of Drp1 mediates $\beta$-amyloid-related mitochondrial fission and neuronal injury," Science, vol. 324, no. 5923, pp. 102-105, 2009.

[137] X. Wang, B. Su, H. Fujioka, and X. Zhu, "Dynamin-like protein 1 reduction underlies mitochondrial morphology and distribution abnormalities in fibroblasts from sporadic Alzheimer's disease patients," American Journal of Pathology, vol. 173, no. 2, pp. 470-482, 2008.

[138] P. Fernández-Vizarra, A. P. Fernández, S. Castro-Blanco et al., "Intra- and extracellular A $\beta$ and PHF in clinically evaluated cases of Alzheimer's disease," Histology and Histopathology, vol. 19, no. 3, pp. 823-844, 2004.

[139] M. Escobar-Henriques and T. Langer, "Mitochondrial shaping cuts," Biochimica et Biophysica Acta (BBA): Molecular Cell Research, vol. 1763, no. 5-6, pp. 422-429, 2006.

[140] A. Neutzner, R. J. Youle, and M. Karbowski, "Outer mitochondrial membrane protein degradation by the proteasome," Novartis Foundation Symposium, vol. 287, pp. 4-14, 2007.

[141] I. V. Kurochkin, "Insulin-degrading enzyme: embarking on amyloid destruction," Trends in Biochemical Sciences, vol. 26, no. 7, pp. 421-425, 2001.

[142] D. J. Selkoe, "Clearing the brain's amyloid cobwebs," Neuron, vol. 32, no. 2, pp. 177-180, 2001.

[143] R. E. Tanzi, R. D. Moir, and S. L. Wagner, "Clearance of Alzheimer's A $\beta$ peptide: the many roads to perdition," Neuron, vol. 43, no. 5, pp. 605-608, 2004.

[144] A. Falkevall, N. Alikhani, S. Bhushan et al., "Degradation of the amyloid $\beta$-protein by the novel mitochondrial peptidasome, PreP," The Journal of Biological Chemistry, vol. 281, no. 39, pp. 29096-29104, 2006.

[145] K. A. Johnson, S. Bhushan, A. Ståhl et al., "The closed structure of presequence protease PreP forms a unique $10000 \AA^{3}$ chamber for proteolysis," The EMBO Journal, vol. 25, no. 9, pp. 1977-1986, 2006.

[146] P. Moberg, A. Ståh, S. Bhushan et al., "Characterization of a novel zinc metalloprotease involved in degrading targeting peptides in mitochondria and chloroplasts," The Plant Journal, vol. 36, no. 5, pp. 616-628, 2003.

[147] N. Mzhavia, Y. L. Berman, Y. Qian, L. Yan, and L. A. Devi, "Cloning, expression, and characterization of human metalloprotease 1: a novel member of the pitrilysin family of metalloendoproteases," DNA and Cell Biology, vol. 18, no. 5, pp. 369-380, 1999.

[148] A. Ståhl, P. Moberg, J. Ytterberg et al., "Isolation and identification of a novel mitochondrial metalloprotease (PreP) that degrades targeting presequences in plants," The Journal of Biological Chemistry, vol. 277, no. 44, pp. 41931-41939, 2002.

[149] A. Ståhl, S. Nilsson, P. Lundberg et al., "Two novel targeting peptide degrading proteases, PrePs, in mitochondria and chloroplasts, so similar and still different," Journal of Molecular Biology, vol. 349, no. 4, pp. 847-860, 2005.

[150] M. Challa, S. Malladi, B. J. Pellock et al., "Drosophila Omi, a mitochondrial-localized IAP antagonist and proapoptotic serine protease," The EMBO Journal, vol. 26, no. 13, pp. 31443156, 2007.

[151] H. J. Huttunen, S. Y. Guénette, C. Peach et al., "HtrA2 regulates $\beta$-amyloid precursor protein (APP) metabolism through endoplasmic reticulum-associated degradation," The Journal of Biological Chemistry, vol. 282, no. 38, pp. 28285-28295, 2007.

[152] D. L. Vaux and J. Silke, "Mammalian mitochondrial IAP binding proteins," Biochemical and Biophysical Research Communications, vol. 304, no. 3, pp. 499-504, 2003.
[153] L. Vande Walle, M. Lamkanfi, and P. Vandenabeele, "The mitochondrial serine protease HtrA2/Omi: an overview," Cell Death and Differentiation, vol. 15, no. 3, pp. 453-460, 2008.

[154] H. Plun-Favreau, K. Klupsch, N. Moisoi et al., "The mitochondrial protease HtrA2 is regulated by Parkinson's diseaseassociated kinase PINK1," Nature Cell Biology, vol. 9, no. 11, pp. 1243-1252, 2007.

[155] D. Harman, "Aging: a theory based on free radical and radiation chemistry," Journal of Gerontology, vol. 11, no. 3, pp. 298-300, 1956.

[156] A. Trifunovic, A. Hansson, A. Wredenberg et al., "Somatic mtDNA mutations cause aging phenotypes without affecting reactive oxygen species production," Proceedings of the National Academy of Sciences of the United States of America, vol. 102, no. 50, pp. 17993-17998, 2005.

[157] M. Vermulst, J. H. Bielas, G. C. Kujoth et al., "Mitochondrial point mutations do not limit the natural lifespan of mice," Nature Genetics, vol. 39, no. 4, pp. 540-543, 2007.

[158] S. E. Schriner, N. J. Linford, G. M. Martin et al., "Extension of murine life span by overexpression of catalase targeted to mitochondria," Science, vol. 308, no. 5730, pp. 1909-1911, 2005.

[159] J. Liu, D. W. Killilea, and B. N. Ames, "Age-associated mitochondrial oxidative decay: improvement of carnitine acetyltransferase substrate-binding affinity and activity in brain by feeding old rats acetyl-L-carnitine and/or $R$ - $\alpha$-lipoic acid," Proceedings of the National Academy of Sciences of the United States of America, vol. 99, no. 4, pp. 1876-1881, 2002.

[160] A. Navarro, C. Gómez, M.-J. Sánchez-Pino et al., "Vitamin $\mathrm{E}$ at high doses improves survival, neurological performance, and brain mitochondrial function in aging male mice," The American Journal of Physiology-Regulatory Integrative and Comparative Physiology, vol. 289, no. 5, pp. R1392-R1399, 2005.

[161] L.-J. Yan and R. S. Sohal, "Mitochondrial adenine nucleotide translocase is modified oxidatively during aging," Proceedings of the National Academy of Sciences of the United States of America, vol. 95, no. 22, pp. 12896-12901, 1998.

[162] A. Bobba, G. Amadoro, V. A. Petragallo, P. Calissano, and A. Atlante, "Dissecting the molecular mechanism by which $\mathrm{NH}_{2}$ htau and $\mathrm{A} \beta 1-42$ peptides impair mitochondrial ANT-1 in Alzheimer disease," Biochimica et Biophysica Acta (BBA)Bioenergetics, vol. 1827, no. 7, pp. 848-860, 2013.

[163] I. Parentini, G. Cavallini, A. Donati, Z. Gori, and E. Bergamini, "Accumulation of dolichol in older tissues satisfies the proposed criteria to be qualified a biomarker of aging," The Journals of Gerontology Series A: Biological Sciences and Medical Sciences, vol. 60, no. 1, pp. 39-43, 2005.

[164] C. Edlund, M. Söderberg, and K. Kristensson, "Isoprenoids in aging and neurodegeneration," Neurochemistry International, vol. 25, no. 1, pp. 35-38, 1994.

[165] P. Navas, J. M. Villalba, and R. de Cabo, "The importance of plasma membrane coenzyme Q in aging and stress responses," Mitochondrion, vol. 7, supplement, pp. S34-S40, 2007.

[166] H. Kraskiewicz and U. Fitzgerald, "IterfERing with endoplasmic reticulum stress," Trends in Pharmacological Sciences, vol. 33, no. 2, pp. 53-63, 2012.

[167] A. Ricobaraza, M. Cuadrado-Tejedor, S. Marco, I. Pérez-Otaño, and A. García-Osta, "Phenylbutyrate rescues dendritic spine loss associated with memory deficits in a mouse model of Alzheimer disease," Hippocampus, vol. 22, no. 5, pp. 1040-1050, 2012. 
[168] A. F. Nunes, J. D. Amaral, A. C. Lo et al., "TUDCA, a bile acid, attenuates amyloid precursor protein processing and amyloid$\beta$ deposition in APP/PS1 mice," Molecular Neurobiology, vol. 45, no. 3, pp. 440-445, 2012.

[169] B. Gong, L.-Y. Zhang, C.-P. Pang, D. S.-C. Lam, and G. H.-F. Yam, "Trimethylamine N-oxide alleviates the severe aggregation and ER stress caused by G98R $\alpha$ A-crystallin," Molecular Vision, vol. 15, pp. 2829-2840, 2009.

[170] M. Boyce, K. F. Bryant, C. Jousse et al., "A selective inhibitor of eIF2 $\alpha$ dephosphorylation protects cells from ER stress," Science, vol. 307, no. 5711, pp. 935-939, 2005.

[171] P. Jiang, M. Gan, A. S. Ebrahim, W.-L. Lin, H. L. Melrose, and S.-H. C. Yen, "ER stress response plays an important role in aggregation of $\alpha$-synuclein," Molecular Neurodegeneration, vol. 5, no. 1, article 56, 2010.

[172] D. Y. Lee, K.-S. Lee, H. J. Lee et al., "Activation of PERK signaling attenuates A $\beta$-mediated ER stress," PLoS ONE, vol. 5, no. 5, Article ID e10489, 2010.

[173] Y. Inokuchi, Y. Nakajima, M. Shimazawa et al., "Effect of an inducer of $\mathrm{BiP}$, a molecular chaperone, on endoplasmic reticulum (ER) stress-induced retinal cell death," Investigative Ophthalmology \& Visual Science, vol. 50, no. 1, pp. 334-344, 2009.

[174] K. Takano, Y. Kitao, Y. Tabata et al., "A dibenzoylmethane derivative protects dopaminergic neurons against both oxidative stress and endoplasmic reticulum stress," American Journal of Physiology-Cell Physiology, vol. 293, no. 6, pp. C1884-C1894, 2007.

[175] I. Yoshida, A. Monji, K.-I. Tashiro, K.-I. Nakamura, R. Inoue, and S. Kanba, "Depletion of intracellular $\mathrm{Ca}^{2+}$ store itself may be a major factor in thapsigargin-induced ER stress and apoptosis in PC12 cells," Neurochemistry International, vol. 48, no. 8, pp. 696-702, 2006.

[176] H. Miura, K. Takano, Y. Kitao et al., "A carbazole derivative protects cells against endoplasmic reticulum (ER) stress and glutathione depletion," Journal of Pharmacological Sciences, vol. 108, no. 2, pp. 164-171, 2008.

[177] E. Kojro, P. Fuger, C. Prinzen et al., "Statins and the squalene synthase inhibitor zaragozic acid stimulate the nonamyloidogenic pathway by suppression of cholesterol synthesis," Journal of Alzheimer's Disease, vol. 20, pp. 1215-1231, 2010.

[178] G. Marwarha, B. Dasari, and O. Ghribi, "Endoplasmic reticulum stress-induced CHOP activation mediates the downregulation of leptin in human neuroblastoma SH-SY5Y cells treated with the oxysterol 27-hydroxycholesterol," Cellular Signalling, vol. 24, no. 2, pp. 484-492, 2012.

[179] H. Wang, A. Megill, K. He, A. Kirkwood, and H.-K. Lee, “Consequences of inhibiting amyloid precursor protein processing enzymes on synaptic function and plasticity," Neural Plasticity, vol. 2012, Article ID 272374, 24 pages, 2012. 


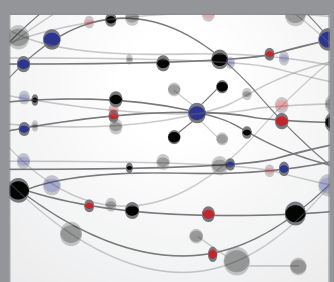

The Scientific World Journal
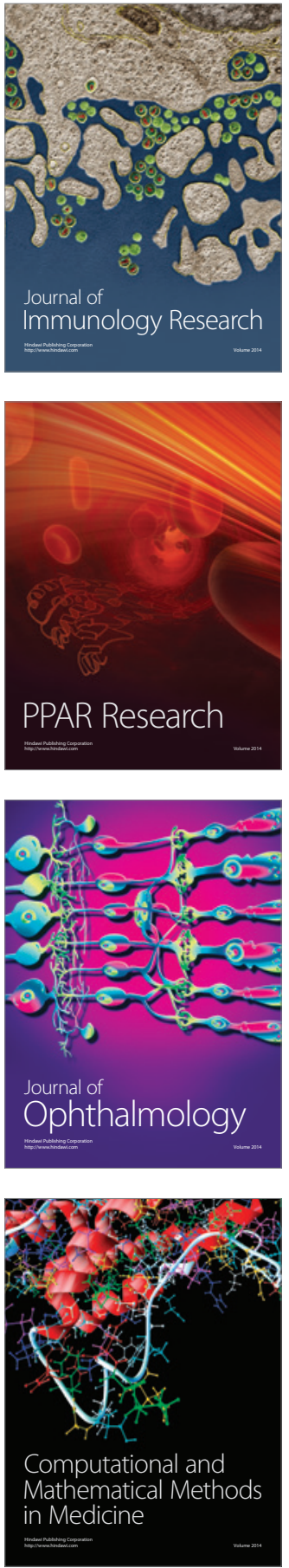

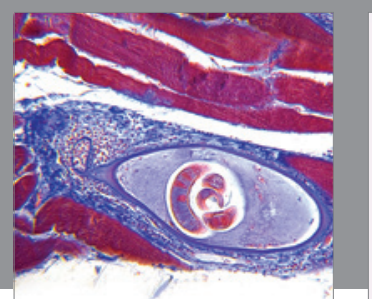

Gastroenterology Research and Practice

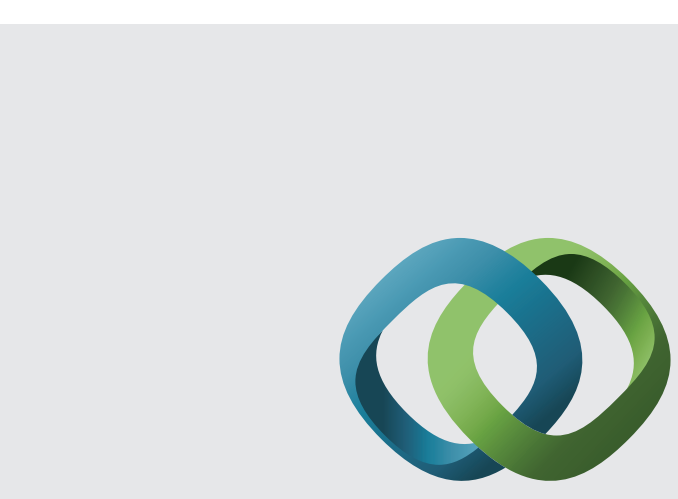

\section{Hindawi}

Submit your manuscripts at

http://www.hindawi.com
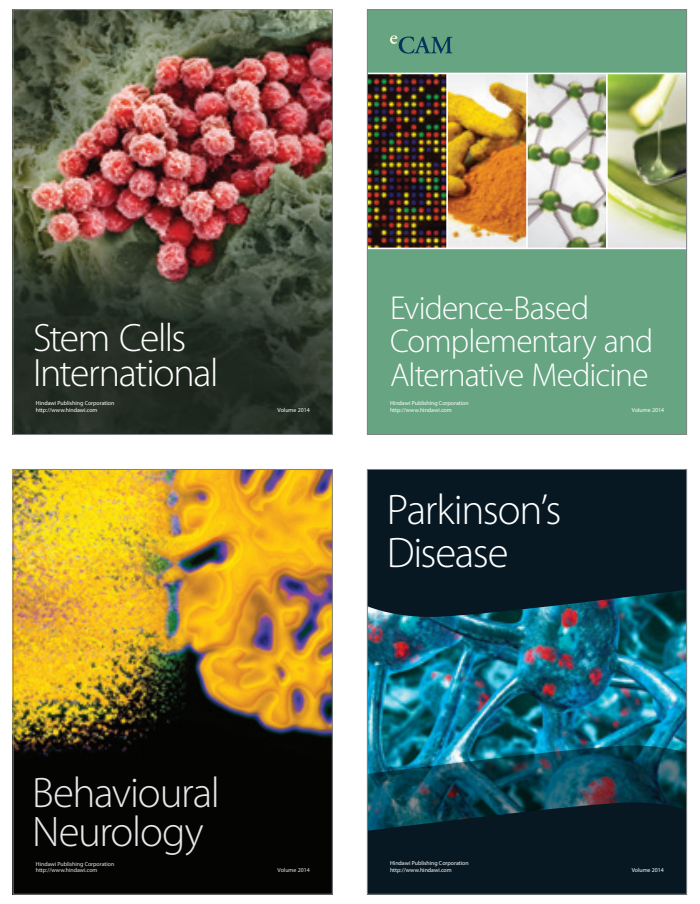
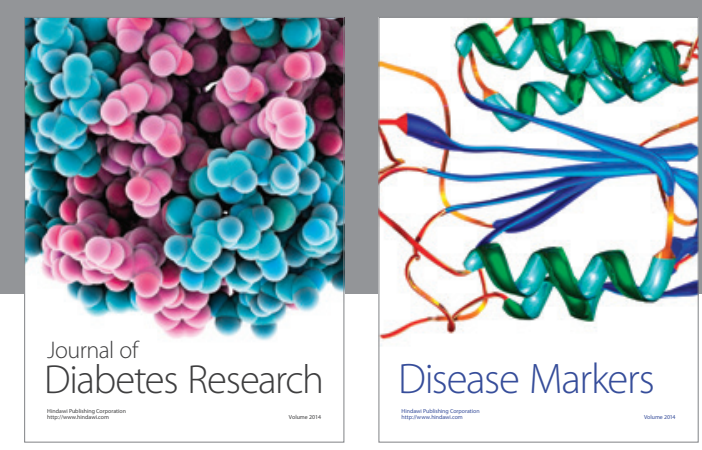

Disease Markers
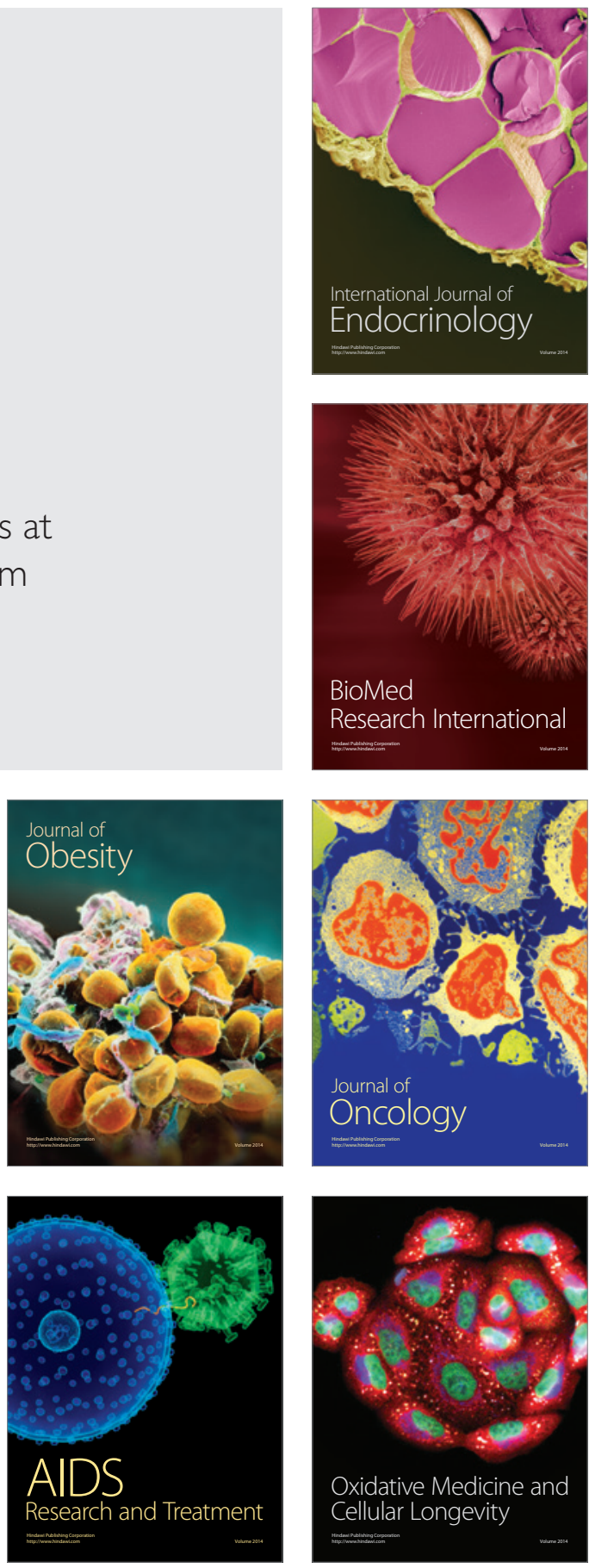